\title{
Specific and General Human Capital in an Endogenous Growth Model
}

\author{
Vahagn Jerbashian ${ }^{1}$ \\ University of Barcelona and CERGE-EI $I^{2}$ \\ Sergey Slobodyan \\ CERGE-EI \\ Evangelia Vourvachaki \\ Bank of Greece ${ }^{3}$
}

\begin{abstract}
In this paper, we define specific (general) human capital in terms of the occupations whose use is spread in a limited (wide) set of industries. We analyze the growth impact of an economy's composition of specific and general human capital, in a model where education and R\&D are costly and complementary activities. The model suggests that a declining share of specific human capital, as observed in the Czech Republic, can be associated with a lower rate of long run growth. We also discuss optimal educational policies in the presence of market frictions.
\end{abstract}

Keywords: Human Capital Types; Economic Growth; Education Policy JEL classification: O52; O40; O49; I20 


\section{Introduction}

Education systems across developed countries are highly diverse with respect to their financing (private vs. public), structure and philosophy (e.g., see OECD, 2010). Because of this, even though there is little variation in terms of the average level of skills within and between developed countries (e.g., in terms of average years of schooling, see the Barro-Lee data), there is important variation in terms of the types of skills developed via education. A number of studies examine the role of the latter for economic outcomes at the individual or aggregate level. One stream of literature differentiates skills according to their "vocational intensity," where a vocation is associated with "practical and technical" skills (e.g., see Krueger and Kumar, 2004a b; Hanushek et al., 2011). Another stream of literature differentiates skills according to the "routine intensity" of the tasks performed as part of an occupation, where high routine intensity is associated with "codifiable" tasks (e.g., see Acemoglu and Autor, 2011; Autor and Dorn, 2013).

We propose an alternative way to horizontally differentiate across skill types in order to analyze the impact of human capital composition on aggregate economic performance. Similarly to existing literature, we exploit the cross-occupational differences. Our point of departure is that our definition derives from cross-industry heterogeneity in the production function: We differentiate human capital skills according to their "industry specificity." This builds a sufficiently general conceptual framework to analyze the impact of shocks, aggregate or industryspecific, skill-biased technology or not.

In particular, we define two distinct types of human capital: "general" and "specific." As general human capital, we define a set of skills that enable individuals to perform generic tasks that are required for production in a wide range of industries (e.g., services skills of managers, manual skills of cleaners). In contrast, specific human capital is defined as a set of skills that enable one to perform highly specialized tasks in a few industries (e.g., the cognitive skills of 
doctors, manual skills of craft workers). ${ }^{4}$

Our classification is used to summarize the facts regarding the employment and education levels of the two human capital types for the Czech economy. This results in a rather uniform level of skills across the specific and general types of human capital, which agrees with our horizontal differentiation of skills. We find that in 2007, approximately 36 percent of the total labor input is comprised of specific human capital. Moreover, the evidence suggests that this share has been steadily falling since the mid-1990s. We find a similar negative trend in the share of specific human capital using German and European employment data.

To illustrate how this horizontal differentiation of human capital can matter for long run growth and welfare, we build up an endogenous growth model, where education and R\&D are costly activities. In the model, both general and specific human capital are used in the final goods production, while only specific human capital can serve as an input into the educational sector and R\&D. This structure highlights that specific, intensive training on the details of production is essential for the ability to innovate or train new human capital. We also explicitly take into account the acclaimed complementarity between basic and/or applied R\&D and education processes and positive externalities in R\&D (e.g., see Griliches, 1992; Nadiri, 1993; Jones and Williams, 1998). ${ }^{5}$ In such a context, there is under-investment in R\&D at the aggregate level because economic agents do not fully internalize the benefits of their R\&D investments. The more the economic agents internalize the benefits of their investments, the more they accumulate specific human capital. Because the latter is the engine of growth, the economy enjoys higher growth.

Our theoretical framework can be used to gain an insight into what can drive the decline in the share of specific human capital that is observed in the Czech economy. We note that to the extent a more centralized (education) system is better suited to accounting for any economywide human capital externalities, our model suggests that the Czech Republic would have been endowed with a high level of specific human capital. ${ }^{6}$ In turn, the gradual decentralization of the 
Czech educational system and interest in individual-level wage returns would imply a declining share of specific human capital, which is consistent with Czech data. In this respect, our model suggests that in an otherwise frictionless and stable economic environment, this trend could involve long run welfare costs expressed in terms of the rate of long run growth.

According to our framework, such a pattern can also hold in the case when the formerly centralized economy involved frictions and over-accumulated specific human capital (e.g., due to political objectives). Admittedly, such explanations may not be well suited, for example, for Germany, where we observe similar trends. In this respect, they are by no means the only potentially plausible explanations for the falling share of specific human capital in this framework. For instance, this framework also suggests that such a pattern can hold if the efficiency of the education process of general human capital increases relative to the efficiency of the education process of specific human capital. This explanation can be reasonable if, for example, the technical change implied by the introduction of IT has increased the efficiency in the education process in the field of Computing, relative to other fields. Meanwhile, more than $90 \%$ of the graduates in this field have general human capital according to our classification and data for the Czech Republic. Clearly, the declining share of the specific human capital in the Czech Republic would not necessarily involve welfare costs if human capital accumulation or an increase in efficiency of general human capital accumulation were complete explanations. ${ }^{7}$

The policy implications derived from the model contribute to the debate concerning the role of public education, $\mathrm{R} \& \mathrm{D}$, and their finance in light of the recent crisis and subsequent budgetary cuts. For example, the United States and the United Kingdom were the first countries to move towards limiting funds for public education, while in the United Kingdom this has been more the case in individual fields such as humanities. The Czech Republic, among other European countries, is also considering taking action in a similar direction. Our results highlight that to the extent the market distortions cannot be excluded, long run welfare can be promoted by introducing subsidies to the returns on human capital, which would encourage its accumulation. 
Our closed economy model abstracts from international knowledge transfer. Admittedly, this can be particularly important for technical progress in the Czech Republic, but relatively less important for the larger economies of Germany and the EU as a whole. In this respect, the model focuses on secular endogenous changes in the share of specific human capital while being consistent with the observed trends in the Czech Republic.

Our paper is related to studies which horizontally differentiate among types of skills and examine the role of such differences for economic outcomes (e.g., Acemoglu and Autor, 2011; Autor and Dorn, 2013). We contribute to these studies by introducing a new way for horizontally differentiating among types of skills. With regards to the model, we relate to the endogenous growth literature that focuses on input accumulation, such as Romer (1990) and Lucas (1988). Closer to our framework is the model presented in Eicher (1996), where educational investment is costly, and technology advances as its by-product. Relative to this literature, our main innovation is that we allow households to choose between the accumulation of general and specific human capital types and to partially internalize the benefits of their inventions.

Finally, our work relates broadly to studies that examine the intra- and inter-temporal tradeoffs between different types of human capital in environments with uncertainty, the introduction of new technologies, or trade. Such mechanisms are analyzed in Autor and Dorn (2013), Krueger and Kumar (2004a b), Gould et al. (2001), and Hummels et al. (2014) among others. Sarychev (1999) offers a theoretical model specific to the transition experience from centrally planned economies to market based ones. Generalizing the economic environment of our model in the spirit of the aforementioned studies would necessarily benefit the relative value of general human capital in our framework. Thereby, our baseline results regarding the benefits from increasing the intensity of specific human capital will not generalize in a straightforward way. Nevertheless, our present framework is sufficiently parsimonious to highlight the benefits of specific human capital in the long run and study the impact of the composition of human capital types on long-term growth and welfare. 
The paper is organized as follows. Section 2 discusses the composition of specific and general human capital in the Czech Republic. Section 3 presents the model and its results. Section 4 concludes.

\section{General and Specific Human Capital: The Case of the Czech}

\section{Republic}

We treat every occupation as defining a particular set of skills that enable the performance of specific tasks that are necessary as a part of the production process. In this respect, occupations tightly define the labor services input in the production of each industry. To the extent that industries differ in their technological needs in terms of the types of labor services, their demand for occupations would also be different. If input/output markets are frictionless, then the observed demand for an occupation by different industries can be used to figure out the degree of an occupation's "industry specificity." We classify an occupation as "specific human capital" if it is used by a limited set of industries, i.e., its employment share exhibits a high degree of concentration across industries. Accordingly, we classify an occupation as "general human capital" if it is used in the production of a wide variety of products, i.e., its employment share has a high degree of dispersion.

In order to systematically summarize how specific and general human capital are produced and used in the Czech economy we employ data from the Czech Labor Force Survey (LFS), quarter 2, 2007. From this survey we obtain information on the number of workers in labor force, their education level and field of education (2-digit ISCED-97), occupation (2-digit ISCO88 ) and the industry in which they are employed (1-digit NACE). Using these data we calculate the number of employed individuals in each occupation-industry cell. Given this matrix, we calculate the within-occupation employment share across industries, within-industry employment shares across occupations, and total employment shares by occupation. 
We use the within-occupation employment shares distribution to calculate a number of concentration statistics. These statistics are then summarized into an average index that increases with the concentration of an occupation across industries. ${ }^{8}$ The correlations across the different concentration statistics employed are presented in Table 2. The ranking of the different occupations in terms of the average index is offered in Table 3. An occupation is classified as requiring specific human capital if the index is greater than the overall threshold, which is set to $0.5 .{ }^{9}$ Table 4 then presents the within-industry employment shares for specific human capital occupations out of total industry labor input in terms of the absolute number of employees.

Further, using the Czech LFS we identify how the workers' background in terms of educational field maps onto occupations in the labor market. We calculate the number of employees in each occupation-education field (2-digit ISCED-97) cell and the within-education field distribution of employees across different occupations. We summarize this information by computing the share of employees in specific human capital occupations (as defined in Table 3) for every education field. Table 5 ranks education fields from the ones where graduates mostly work in specific human capital occupations (Health and Teacher Training and Educational Science) to the ones where graduates are mostly employed in general human capital occupations (Law and Computing).

Finally, we summarize the education levels across all occupations and the two types of human capital in Table 6 and Table 7. We report the within-occupation shares of those who have basic education but no higher (ISCED-97 0-2), those who have secondary education but no higher (ISCED-97 3-4), and those who have higher than secondary education (ISCED-97 5-6).

The results of this exercise are rather intuitive. As an illustration, life science and health professionals, such as medical doctors, and teaching professionals, including university professors, are classified as specific human capital (see Table 3). This is because they are employed almost exclusively in the health and education sectors. These occupations require a high level of skills (see Table 6). The training for life science and health professionals comes almost exclusively 
from the health field. ${ }^{10}$ In contrast, teaching professionals graduate from a wide set of fields ranging from business and administration to engineering. Another highly skilled group, corporate managers, is classified as general human capital since they are almost evenly distributed across all industries. They graduate from a wide set of fields. We also observe seemingly counterintuitive cases of highly skilled groups (lawyers), which are employed by a wide variety of industries despite being trained (almost) exclusively in the educational field of law and, thus, classified as general human capital.

Table 7 shows that there is very little difference in the average level of skills between specific and general human capital occupations. This suggests that our study of horizontal differentiation is indeed capturing the effects differing from those caused by the more commonly studied vertical split (i.e., low- vs. highly-skilled) of human capital.

The overall employment (use) share of specific human capital is $36.4 \%$ for $2007 .{ }^{11}$ Figure 1 illustrates how the employment share of specific human capital has evolved over the period 19942007 in the Czech Republic. In this figure, we take the information for the period 1994-2002 from Jeong et al. (2008) and interpolate for the Czech Republic for the period 2003-2006. ${ }^{12}$

There is a clear downward trend with the share falling by 5 percentage points over the course of the entire period. The downward trend in the employment of specific human capital is not particular to the Czech Republic since Germany matches it over the course of 1992-2002. ${ }^{13}$

We further investigate the composition of new graduates (i.e., the potential new entrants into the labor force) in terms of specific and general human capital. In particular, we examine the presence of graduates among the most specific human capital intensive education fields, as identified from the Czech LFS data, using the EUROSTAT educational data for 2007 and 2000. We highlight the education fields where the majority of graduates (more than $50 \%$ ) end up in specific human capital related occupations according to our employment data. In 2007, $34.5 \%$ of total graduates in the Czech Republic graduated from fields that intensively produce specific human capital. The corresponding share in 2007 for Germany was $35 \%$ and $34 \%$ for the 
Euro area. In 2000, the share for the Czech Republic is also close to its German counterpart (33.1\% and $30.6 \%$ respectively). We do not have data for sufficiently long period to comment on the existence of any systematic time patterns. Moreover, there are further limitations in this respect, as educational data are bound to lag behind labor market developments due to demographics, difficulties in changing institutions and culture, uncertainty, etc.

Overall, the data presented here show that the Czech Republic has changed its composition of human capital types in a way that closely matches its neighbors. This outcome may strike one as surprising as the Czech Republic, among other former transition and Central European countries, is often presented as a "vocational" economy. For example, in their recent review Hanushek et al. (2011) show that the Czech Republic, Hungary, and Poland, together with Germany and Switzerland, feature as top apprenticeship countries in Europe, with $72 \%$ of the male population completing "vocational" education and the rest completing "general" education. Notably though, they define the latter as "tertiary type-A programs [...] largely theory-based [...] designed to provide sufficient qualifications for entry to advanced research programs and professions with high skill requirements"(p. 9). ${ }^{14}$ In this respect, their definition is tied more to the skills level than to the skills type and the degree to which skills are used for the production of a wide range of products, which is our own primary focus. This highlights the importance of the original choice of the definition for specific human capital.

\section{The Model}

The final goods $(Y)$ producers use physical capital $(K)$, specific human capital $\left(H_{s}\right)$ and general human capital $\left(H_{g}\right)$, in order to produce homogenous goods.

The economy is populated by a continuum of infinitely lived and identical households of mass one. The representative household owns all types of physical and human capital and derives utility from the consumption $(C)$ of final goods. The household finances its consumption expenditures with the labor income and interest earned on capital. The household rents its two 
types of human capital and physical capital at the prevailing market prices $\left(w_{s}, w_{g}\right.$, and $r$, respectively).

The household can accumulate either type of its human capital through education. Having intensive training on the details of production, the specific human capital is the necessary input in the education process. Each human capital has a different accumulation process in the education sector (i.e., different schooling function). ${ }^{15}$

Human capital employed in the schooling of specific human capital also engages in R\&D. This process captures the $\mathrm{R} \& \mathrm{D}$ in education/academia-related institutions. Innovation generated through this process improves the quality (or the efficiency) of the physical capital.

Given that the household owns physical capital and the innovations are embodied in it, the household (at least partly) internalizes the effect of this $R \& D$ process on physical capital. In the spirit of Romer (1990) and Lucas (1988), the household has decreasing returns from this process; however, the externalities that stem from others' involvement in R\&D make the returns constant at the aggregate level. These externalities might arise from knowledge sharing among researchers and imperfect property rights. ${ }^{16}$

\subsection{Final Goods Sector}

The production function of final goods is given by

$$
\begin{aligned}
& Y=\lambda_{Y} H_{g}^{\gamma_{1}}\left[\left(u_{Y}^{s} H_{s}\right)^{\gamma_{2}} K^{1-\gamma_{2}}\right]^{1-\gamma_{1}}, \\
& \lambda_{Y}>0,1>\gamma_{1}>0,1>\gamma_{2}>0,
\end{aligned}
$$

where $\lambda_{Y}$ is an exogenous productivity level, and $u_{Y}^{s}$ is the share of specific human capital employed in the production of final goods.

Setting the final goods as the numeraire, the optimization problem of a representative pro- 
ducer is given by

$$
\begin{aligned}
& \max _{H_{g}, u_{Y}^{s} H_{s}, K}\left\{Y-w_{g} H_{g}-w_{s} u_{Y}^{s} H_{s}-r K\right\}, \\
& \text { s.t. (1). }
\end{aligned}
$$

The resulting optimal rules are the final goods producer's demands for general and specific types of human capital and physical capital:

$$
\begin{aligned}
& w_{g} H_{g}=\gamma_{1} Y, \\
& w_{s} u_{Y}^{s} H_{s}=\left(1-\gamma_{1}\right) \gamma_{2} Y, \\
& r K=\left(1-\gamma_{1}\right)\left(1-\gamma_{2}\right) Y .
\end{aligned}
$$

\subsection{Education Sector}

Specific and general types of human capital have different accumulation processes (schooling functions), where the only input is the specific human capital. The accumulation processes are

$$
\begin{aligned}
& \dot{H}_{s}=\lambda_{s} u_{s}^{s} H_{s}, \\
& \dot{H}_{g}=\lambda_{g} u_{g}^{s} H_{s},
\end{aligned}
$$

respectively, where $\lambda_{s}, \lambda_{g}>0$ are exogenous productivity levels, and $u_{s}^{s}$ and $u_{g}^{s}$ are the shares of specific human capital employed in the respective accumulation processes.

The human capital employed in the accumulation of specific human capital also produces new technology $\Lambda$ according to the following rule:

$$
\dot{\Lambda}=\delta\left(u_{s}^{s} H_{s}\right)^{\gamma_{3}},
$$

where $1 \geq \gamma_{3} \geq 0$, and $\delta$ is a productivity level that is exogenous from an individual perspective. 
The technology thus generated improves the quality of physical capital:

$$
K=\Lambda k
$$

where $k$ is normalized to 1 . This $R \& D$ process can be thought to represent basic and applied R\&D carried in education/academia-related institutions (e.g., by teaching professionals).

At the aggregate level, there are constant returns in the R\&D process, and $\delta$ is given by

$$
\delta=\lambda_{\Lambda}\left(u_{s}^{s} H_{s}\right)^{1-\gamma_{3}}
$$

where $\lambda_{\Lambda}>0$ is an exogenous productivity level. Therefore, $1-\gamma_{3}$ equals the degree of externalities that stem from others' involvement in $R \& D$. In the limiting case when $\gamma_{3}=1$, there are no such externalities, whereas when $\gamma_{3}=0$, the R\&D process is a pure externality.

We also discuss two extensions of this R\&D process. In Appendix 5, we treat the allocation of specific human capital to R\&D activity as a (separate) choice variable, which makes the comparative statics easy to derive. In Appendix 6, we include small exponents of physical capital and general human capital in the R\&D and education processes. Our main results carry over in both these extensions.

\subsection{The Households}

The representative household has a standard CIES utility function with an inter-temporal substitution parameter $\frac{1}{\theta}>0$. It discounts the future streams of utility with rate $\rho>0$. The lifetime utility of the household is given by

$$
U=\int_{0}^{+\infty} \frac{C_{t}^{1-\theta}-1}{1-\theta} \exp (-\rho t) d t
$$


The household's decisions follow its preferences and satisfy its budget constraint:

$$
\begin{aligned}
& 0=r K+w_{s} u_{Y}^{s}\left(1+\tau_{Y}^{s}\right) H_{s}+w_{g}\left(1+\tau_{Y}^{g}\right) H_{g}-C-T, \\
& 1 \geq \tau_{Y}^{s} \geq-1,1 \geq \tau_{Y}^{g} \geq-1,
\end{aligned}
$$

where the triple $\left\{\tau_{Y}^{s}, \tau_{Y}^{g}, T\right\}$ represents government policy, consisting of proportional taxes (or subsidies) on earnings from specific and general human capital employed in the production of final goods, and a lump-sum tax $T$. The tax $T$, which is needed to balance the government budget, in equilibrium is given by

$$
T=w_{s} u_{Y}^{s} \tau_{Y}^{s} H_{s}+w_{g} \tau_{Y}^{g} H_{g}
$$

The sum of shares of specific capital in the education and final goods sectors satisfies

$$
1 \geq u_{Y}^{s}+u_{s}^{s}+u_{g}^{s}
$$

The inter-temporal choice of the household is between allocating specific human capital to the final goods sector and allocating it to the education sector for factor accumulation. Patient households "save" more by investing into specific human capital $H_{s}$. The household's optimal problem is

$$
\begin{aligned}
& \max _{u_{Y}^{s}, u_{g}^{s}, C}\left\{\int_{0}^{+\infty} \frac{C_{t}^{1-\theta}-1}{1-\theta} \exp (-\rho t) d t\right\} \\
& \text { s.t. } \\
& (12),(6),(7),(8),(9),(14), \\
& H_{s}(0), H_{g}(0), \Lambda(0)>0-\text { given. }
\end{aligned}
$$


Assigning shadow values $\left\{q_{i}\right\}$ to constraints (12), (6), (7), and (8), the decision rules that follow from the household's optimization are

$$
\begin{aligned}
& C^{-\theta}=q_{1}, \\
& q_{1} w_{s}\left(1+\tau_{Y}^{s}\right) H_{s}=q_{2} \frac{\dot{H}_{s}}{u_{s}^{s}}+q_{4} \gamma_{3} \frac{\dot{\Lambda}}{u_{s}^{s}}, \\
& q_{3} \frac{\dot{H}_{g}}{u_{g}^{s}}=q_{2} \frac{\dot{H}_{s}}{u_{s}^{s}}+q_{4} \gamma_{3} \frac{\dot{\Lambda}}{u_{s}^{s}}, \\
& \dot{q}_{2}=q_{2} \rho-\left[q_{1} w_{s} u_{Y}^{s}\left(1+\tau_{Y}^{s}\right)+q_{2} \frac{\dot{H}_{s}}{H_{s}}+q_{3} \frac{\dot{H}_{g}}{H_{s}}+q_{4} \gamma_{3} \frac{\dot{\Lambda}}{H_{s}}\right], \\
& \dot{q}_{3}=q_{3} \rho-q_{1} w_{g}\left(1+\tau_{Y}^{g}\right), \\
& \dot{q}_{4}=q_{4} \rho-q_{1} r k .
\end{aligned}
$$

The first optimal decision is for the consumption path. The next two describe the allocations of specific human capital in the final goods and education sectors, where the second term on the right-hand side of both expressions is the value stemming from R\&D activity. ${ }^{17}$ The remaining decision rules describe the returns on the accumulation of the two types of human capital and technology/capital. ${ }^{18}$ The household's optimal choices also satisfy transversality conditions:

$$
\begin{aligned}
& \lim _{t \rightarrow+\infty} q_{2} H_{s} \exp (-\rho t)=0, \\
& \lim _{t \rightarrow+\infty} q_{3} H_{g} \exp (-\rho t)=0, \\
& \lim _{t \rightarrow+\infty} q_{4} K \exp (-\rho t)=0 .
\end{aligned}
$$

Using the letter $g$ for the growth rates of variables and combining expressions (3), (4), (5), (16), and (17), the returns on accumulation of all types of asset holdings of the household can 
be rewritten as

$$
\begin{aligned}
& -g_{q_{2}}=\lambda_{s}+\lambda_{\Lambda} \gamma_{3} \frac{q_{4}}{q_{2}}-\rho, \\
& -g_{q_{3}}=\lambda_{g} \frac{1+\tau_{Y}^{g}}{1+\tau_{Y}^{s}} \frac{\gamma_{1}}{\left(1-\gamma_{1}\right) \gamma_{2}} \frac{H_{s}}{H_{g}} u_{Y}^{s}-\rho, \\
& -g_{q_{4}}=\frac{1-\gamma_{2}}{\gamma_{2}} \frac{1}{1+\tau_{Y}^{s}} \frac{H_{s}}{\Lambda} u_{Y}^{s}\left(\lambda_{s} \frac{q_{2}}{q_{4}}+\gamma_{3} \lambda_{\Lambda}\right)-\rho .
\end{aligned}
$$

The ratio $\frac{q_{4}}{q_{2}}$ shows the value from relaxing the constraint for $\dot{\Lambda},(8)$, compared to the value from relaxing the constraint for $\dot{H}_{s}$, (6). According to (21) and (23), the return on the accumulation of specific human capital, $-g_{q_{2}}$, increases with that ratio, whereas the return on the accumulation of technology, $-g_{q_{4}}$, declines with it.

\section{Features of the Dynamic Equilibrium}

The main results regarding the behavior of the economy are the following.

Proposition 1. The balanced growth path growth rates and allocations of the economy can be derived from the root(s) of the following quadratic polynomial in $\frac{q_{4}}{q_{2}}$.

$$
\begin{aligned}
P\left(\frac{q_{4}}{q_{2}}\right)= & {\left[\theta+\frac{1+\tau_{Y}^{g}}{1+\tau_{Y}^{s}} \frac{\gamma_{1}}{\left(1-\gamma_{1}\right) \gamma_{2}}+\frac{1-\gamma_{2}}{\gamma_{2}} \frac{1}{1+\tau_{Y}^{s}} \gamma_{3}\right] \frac{1}{\theta} \lambda_{\Lambda} \gamma_{3}\left(\frac{q_{4}}{q_{2}}\right)^{2} } \\
& +\left\{\left[1+\frac{1}{\theta} \frac{1+\tau_{Y}^{g}}{1+\tau_{Y}^{s}} \frac{\gamma_{1}}{\left(1-\gamma_{1}\right) \gamma_{2}}\right]\left(\lambda_{s}-\rho\right)+\rho\right. \\
& \left.+\frac{\lambda_{s}(2-\theta)-\rho}{\theta} \frac{1-\gamma_{2}}{\gamma_{2}} \gamma_{3} \frac{1}{1+\tau_{Y}^{s}}\right\} \frac{q_{4}}{q_{2}} \\
& -\frac{1-\gamma_{2}}{\gamma_{2}} \frac{1}{1+\tau_{Y}^{s}} \frac{\lambda_{s}}{\lambda_{\Lambda}}\left[\lambda_{s}-\frac{1}{\theta}\left(\lambda_{s}-\rho\right)\right]
\end{aligned}
$$

Proof. See Appendix 1.

Since the quadratic coefficient is positive, a sufficient condition for two real roots is a negative free term. It is sufficient to have

$$
\theta \geq 1
$$


in order for the free term to be negative. This condition implies that the household needs to have a relatively low elasticity of inter-temporal substitution. It is a common condition that ensures balanced growth in multi-sector growth models. In our framework, it implies also that there is only one positive root. Hereafter, it is assumed that (25) holds.

Proposition 2. In the decentralized equilibrium on the balanced growth path, all quantities grow at the same rate

$$
g=\frac{1}{\theta}\left(\lambda_{s}+\lambda_{\Lambda} \gamma_{3} \frac{q_{4}}{q_{2}}-\rho\right)
$$

where $\frac{q_{4}}{q_{2}}$ is the positive root of the polynomial $P\left(\frac{q_{4}}{q_{2}}\right)$. Moreover, all relative prices are constant, and the growth rates of shadow values $q_{1}, q_{2}, q_{3}$, and $q_{4}$ are equal.

Proof. See Appendix 1, which also offers the system of equations that can be solved for the relative allocations

Therefore, the condition that ensures a positive growth rate of consumption on the balanced growth path is

$$
\lambda_{s}+\lambda_{\Lambda} \gamma_{3} \frac{q_{4}}{q_{2}}>\rho
$$

Together with (25) this condition is necessary in order for the transversality conditions to hold and for the lifetime utility to be bounded. Hereafter, it is assumed that (27) holds for any value of $\gamma_{3}$, which is equivalent to assuming that $\lambda_{s}>\rho$.

Proposition 3. A sufficient condition for saddle path stability is

$$
\left(1-\gamma_{2}\right) \frac{\gamma_{1}}{\gamma_{2}} \frac{1+\tau_{Y}^{g}}{1+\tau_{Y}^{s}}-\left(1-\gamma_{1}\right) \gamma_{2}-\gamma_{1}<\frac{1}{\theta-1}
$$

Proof. See Appendix 2.

If the economy starts not at the balanced growth path level, under this condition it experiences smooth and monotonic transition to balanced path. Hereafter, it is assumed that (28) holds. ${ }^{19}$ 
In order to further highlight the properties of the decentralized equilibrium, Table 1 offers the (main) comparative statics for balanced growth path quantities (ratios) and rates of growth. Some of the derivatives in this table are obtained using numerical methods since the analytical derivations become cumbersome due to high non-linearity of equations (for further details see Appendix 1). The non-linearity arises because the return on the accumulation of specific human capital, $-g_{q_{2}}$, is linear in $\frac{q_{4}}{q_{2}}$, while the return on accumulation of technology, $-g_{q_{4}}$, is linear in the inverse of $\frac{q_{4}}{q_{2}}$, but on the balanced growth path the returns need to be equal. When R\&D is a pure externality (i.e., $\left.\gamma_{3}=0\right),-g_{q_{2}}$ does not depend on $\frac{q_{4}}{q_{2}}$, and the comparative statics are easily computed (see Appendix 4). ${ }^{20}$

Focusing on the most interesting comparative statics, according to Table 1, the share of specific human capital allocated to the training of specific human capital, $u_{s}^{s}$, increases with $\gamma_{3}$. This happens since higher $\gamma_{3}$ implies a higher internalized benefit from R\&D and, thus, a larger incentive for accumulating specific human capital. This is also the reason for the ratio of specific and general human capitals, $\frac{H_{s}}{H_{g}}$, as well as the share of specific human capital, $\frac{H_{s}}{H_{g}+H_{s}}$, increase with $\gamma_{3}$. Meanwhile, the growth rate, $g$, increases with $\gamma_{3}$ since the driver of growth in this economy is the accumulation of specific human capital.

These results carry over to the case when we include small exponents of physical capital and general human capital in the R\&D and education processes (see Appendix 6). Intuitively, this holds because increasing $\gamma_{3}$ increases the return on specific human capital accumulation more than the return on general human capital accumulation when the share of specific human capital in the $\mathrm{R} \& \mathrm{D}$ and education processes is larger than the combined share of general human capital and physical capital. Moreover, higher returns on human capital accumulation increases the incentives to save and the growth of final output. ${ }^{21}$ 


\subsection{Possible Explanations for the Falling Share of Specific Human Capital in the Czech Republic}

In this framework, the share of specific human capital will gradually decline if its initial value is higher than the balanced growth path value. We further present some seemingly plausible explanations for such a relation as observed in the Czech Republic.

An unanticipated decline in $\gamma_{3}$ matches this relationship. The intuition behind this is that more centralized mechanisms are, arguably, better at accounting for possible economy-wide externalities. The decentralization process in the Czech Republic, therefore, would have increased the effective degree of externalities, $1-\gamma_{3}$. According to Table 1 such an unanticipated decline would also imply a decline in the rate of long run growth. Evidently, such a change in $\gamma_{3}$ could also stem from, for example, the spread of information and communication technologies which can ease the access to intellectual property and might dilute the strength of intellectual property rights.

This is by no means the only plausible explanation according to Table 1. Another seemingly reasonable explanation for the decline in the share of specific human capital can be an unanticipated increase in the efficiency of the education process of general human capital, $\lambda_{g}$. Such an explanation is plausible to the extent that the introduction and use of information and communication technologies could have increased the productivity of the education process in the Computing field relative to other fields, as our data suggest that almost all graduates in this field have general human capital. The share of specific human capital would be higher than its balanced growth path value also if the centralized economy involved frictions and overaccumulated specific human capital. Clearly, if any of these two were exhaustive explanations, the declining share would not necessarily involve any welfare costs.

According to Table 1, changes in policy parameters $\tau_{Y}^{s}$ and $\tau_{Y}^{g}$ can also be responsible for the changes in the share of specific human capital as observed in Czech economy. In our framework, these policy parameters can be thought to represent education policy since they affect the value 
and incentives of accumulating human capital relative to earning wage returns. For example, higher $\tau_{Y}^{s}$ implies lower incentives to accumulate human capital and in that sense corresponds to lower education subsidies. According to Table 1, higher $\tau_{Y}^{s}$ implies a higher share of specific human capital. In turn, if $\tau_{Y}^{s}$ and $\tau_{Y}^{g}$ increase simultaneously then the share of specific human capital declines. Public expenditures on education (\% of GDP) in the Czech Republic were quite volatile in the period of 1994 - 2007 and have declined by around $10 \%$ according to WDI data. If this corresponds to a higher $\tau_{Y}^{s}$ but constant $\tau_{Y}^{g}$ then, according to the model, it cannot match the observed change in the share of specific human capital. However, if it corresponds to a simultaneous increase in $\tau_{Y}^{s}$ and $\tau_{Y}^{g}$, then it can be another plausible explanation. Data limitations do not allow us to check whether $\tau_{Y}^{s}$ and $\tau_{Y}^{g}$ have changed simultaneously, although that seems quite reasonable. It corresponds to a horizontal decline in subsidies to education of specific and general types of human capital.

We perform a very simplistic calibration exercise in order to check whether required changes in $\gamma_{3}, \lambda_{g}$, and $\tau_{Y} \equiv \tau_{Y}^{s}=\tau_{Y}^{g}$ for matching the observed trend are reasonable. In this exercise, the values of utility parameters and the share of capital compensation are obtained from Hloušek (2012). The values of these parameters are $\rho=0.05, \theta=1$, and $\left(1-\gamma_{1}\right)\left(1-\gamma_{2}\right)=0.3$, correspondingly. We use data from labor force survey for income deciles in order to calibrate the share of general human capital compensation, $\gamma_{1}$. More precisely, we use the value of average income decile of persons with general human capital in the Czech Republic in 2009 (such data are available from 2009). We obtain that the share of general human capital compensation out of total human capital compensation is 0.55 . This, together with the share of (physical) capital compensation, implies that $\gamma_{1}=0.39$ and $\gamma_{2}=0.51$. To pin down the value of $\gamma_{3}$ and $\tau_{Y}$, we assume that externalities were relatively weak in 1994 so that $\gamma_{3}=0.9$ and normalize $\tau_{Y}=0$.

Assigning $\lambda_{s}=0.1$ allows us to keep the long-term growth rate in the model economy below double digits and to maintain regularity conditions. Further, we assume that the Czech economy was on a balanced growth path in 1994, which admittedly is a bold assumption, and derive the 
value of $\lambda_{g}$ from the observed share of specific human capital, $41.5 \%$. The value obtained for $\lambda_{g}$ is 0.67 , which is significantly larger than the value of $\lambda_{s}$. In terms of the model economy, this corresponds to a more difficult training process for specific human capital relative to general human capital.

Similarly, we assume that the Czech economy was on a balanced growth path in 2007. In 2007 the share of specific human capital was $36.4 \%$. We attempt to match this with a change in either $\gamma_{3}$ or $\lambda_{g}$ or $\tau_{Y}$. Our numerical exercise implies that either $\gamma_{3}$ needs to decline to 0.51 or $\lambda_{g}$ needs to increase to 0.84 or $\tau_{Y}$ has to increase to 0.76 . Although the required change of $\tau_{Y}$ is relatively large, the required changes of $\gamma_{3}$ and $\lambda_{g}$ seem to be not extraordinarily high and fall into a reasonable ballpark. ${ }^{22}$

\subsection{Policy Inference}

When $\gamma_{3}=1$ and the tax rates are zero, the decentralized equilibrium solution coincides with the social planner's solution. However, when $\gamma_{3}<1$ in the decentralized equilibrium the benefits from allocating specific human capital to the education sector that stems from the increased rate of innovation cannot be fully appropriated by the household. This distortion arises because of the decreasing returns in education at the individual level. As a result, for any $u_{s}^{s}$, specific human capital earns higher returns in social optimum than in the decentralized equilibrium. Thus, at least on the balanced growth path, the socially optimal growth rate and the share of specific human capital are all higher than their counterparts in the decentralized economy.

Taxing earnings from both types of human capital uniformly can increase the growth rate of the decentralized economy to its socially optimal level since it can increase human capital allocation to eduction and R\&D. The following proposition elaborates this statement.

Proposition 4. The policy in the decentralized equilibrium that delivers the same allocations 
and growth rates as in the social planner's solution is

$$
\begin{aligned}
& 1+\tau_{Y}^{s}=\gamma_{3}, \\
& 1+\tau_{Y}^{g}=1+\tau_{Y}^{s} .
\end{aligned}
$$

Under this policy,

$$
q_{4} \gamma_{3}=q_{4}^{S P}
$$

where SP stands for the social planner's solution.

Proof. See Appendix 3

This result is intuitive. The tax rate $\tau_{Y}^{s}$ corrects the distortion in the value of allocating specific human capital to its accumulation that stems from an increase in the innovation rate. It equates the shadow value of specific human capital in the decentralized equilibrium adjusted for the externality, $q_{4} \gamma_{3}$, to its shadow value in the social optimum, $q_{4}^{S P}$. Meanwhile, the equality $\tau_{Y}^{g}=\tau_{Y}^{s}$ keeps the optimal rule (22) in accordance with the socially optimal rule, where there are no tax rates. The reason why $\tau_{Y}^{g}$ and $\tau_{Y}^{s}$ need to be equal is that there are no frictions on the production side; therefore, the ratio of wages is not distorted. Such a horizontally homogenous education policy retains the optimal ratio. However, it reduces the value of the specific human capital less than the value of the general human capital since the former also conducts R\&D. Given the nature of the externalities, such a disproportionate change is essential for attaining socially optimal outcomes. ${ }^{23}$

\subsection{Discussion of the Model}

As noted in the introduction, for the sake of highlighting the role of specific human capital as the engine of growth in the most parsimonious way, we built a model that does not capture the inherent flexibility of general human capital. This implies that our findings regarding the 
benefits from accumulating specific human capital might be biased upwards. ${ }^{24}$ However, our present framework still captures how the choice of the type of human capital is tied to a choice between current and future consumption levels: The higher the utility cost of sacrificing present consumption is, the more likely the economy would be relatively abundant in general human capital.

In this respect, we view the present model as the first step towards building a generalized theoretical framework that would capture more aspects of the economic environment. Importantly, this would involve, first, building a multi-sector production structure and second, adding sources of aggregate uncertainty. The former allows us to model explicitly the defining feature of general human capital, i.e., its usability across a variety of production sectors. The latter allows us to analyze explicitly the advantage of general human capital over specific one, namely its ability to adjust to new economic conditions. Such a framework would necessarily complicate the inter-temporal trade-off between the two types of human capital to a significant degree, making growth and welfare implications non-straightforward. Our conjecture is that for highly stable economic environments, the results would be qualitatively similar to those of our present model. This extension is left for future research.

\section{Conclusions}

In this paper, we consider industry-specificity as a distinct source of human capital heterogeneity that is defined irrespective of the skill-level accumulated through education. Accordingly, we define general and specific human capital. We apply our definitions to study the composition of the production structure and education in the Czech Republic in terms of the two types of human capital and find a declining employment (use) share of specific human capital in the Czech economy.

Moreover, we develop a stylized model that captures trade-offs between the two types of human capital and the importance of specific human capital as the source of long run growth. 
Through the lens of the model, we may interpret the declining share of specific human capital as an aspect of transition from the previous centralized system of education and production to a market-based mechanism.

In an environment with frictions in $\mathrm{R} \& \mathrm{D}$, we discuss optimal educational policies. Our model suggests that providing public funds for $\mathrm{R} \& \mathrm{D}$ and education could be optimal in the presence of the R\&D externality, which corresponds to a common policy implication in endogenous growth models with externalities. More empirical work is needed to establish the position of the Czech and European economies with respect to an optimal specific human capital share.

\section{Tables and Figures}

Table 1: Comparative Statics

\begin{tabular}{|c|c|c|c|c|c|c|c|c|c|c|}
\hline & & $q_{4} / q_{2}$ & $q_{3} / q_{2}$ & $H_{s} / H_{g}$ & $H_{s} / \Lambda$ & $g$ & $u_{s}^{s}$ & $u_{g}^{s}$ & $u_{Y}^{s}$ & $u_{s}^{s} / u_{g}^{s}$ \\
\hline$\rho$ & {$[0.001,0.09]$} & + & + & - & 0 & - & - & \pm & + & - \\
\hline$\theta$ & {$[1,10]$} & + & + & - & 0 & - & - & \pm & + & - \\
\hline$\gamma_{1}$ & {$[0.01,0.99]$} & - & - & - & 0 & - & - & + & - & - \\
\hline$\gamma_{2}$ & {$[0.01,0.99]$} & - & - & \pm & 0 & - & - & \pm & + & \pm \\
\hline$\gamma_{3}$ & {$[0.01,0.99]$} & \pm & + & + & 0 & + & + & \pm & - & + \\
\hline$\lambda_{s}$ & {$[0.1,10]$} & \pm & + & + & + & + & + & \pm & - & + \\
\hline$\lambda_{g}$ & & 0 & - & - & 0 & 0 & 0 & 0 & 0 & 0 \\
\hline$\lambda_{s}, \lambda_{s} \equiv \lambda_{g}$ & {$[0.1,10]$} & \pm & - & + & + & + & + & \pm & - & + \\
\hline$\lambda_{\Lambda}$ & & - & 0 & 0 & - & 0 & 0 & 0 & 0 & 0 \\
\hline & {$[-0.99,0.99]$} & - & - & + & 0 & - & - & - & + & + \\
\hline$\tau_{Y}^{s}, \tau_{Y}^{g} \equiv \tau_{Y}^{s}$ & {$[-0.99,0.99]$} & - & - & - & 0 & - & - & \pm & + & - \\
\hline
\end{tabular}

Note: The sign + means a positive relationship, - negative, 0 no relationship, and \pm means that the relationship depends on model parameters. Some of these comparative statics are derived with a numerical exercise (see for details Appendix 1 ). The intervals for parameter values used in the exercise are offered in the table. In this exercise, we form a multidimensional grid of parameter values using 5 equidistant points from each interval. We perform the exercise for those points from that multidimensional grid that satisfy parameter restrictions (27) and (28). 
Table 2: Correlation Among Concentration Statistics

\begin{tabular}{lrrrrr}
\hline \hline & CI & CV & HI & EI & EXI \\
\hline CI & & & & & \\
CV & 0.955 & & & & \\
HI & 0.936 & 0.991 & & & \\
EI & -0.869 & -0.830 & -0.823 & & \\
EXI & 0.861 & 0.831 & 0.850 & -0.926 & \\
GI & 0.919 & 0.979 & 0.950 & -0.831 & 0.787 \\
\hline
\end{tabular}

Note: This table offers pair-wise correlations among concentration measures computed for within-occupation employment shares distribution. The concentration measures are average concentration index (CI), coefficient of variation (CV), Herfindahl index (HI), entropy index (EI), exponential index (EXI), and Gini index (GI). In order to construct CI, we define dummy variables for each of the concentration measures which are equal to 1 for higher than median values of the concentration measures, 0 otherwise. The average concentration index (CI) is the average of these dummy variables.

Table 3: Assignment of Occupations into Specific and General Human Capital Types

\begin{tabular}{|c|c|c|}
\hline Occupation & $\begin{array}{l}\text { Specific }=1 ; \\
\text { General }=0\end{array}$ & Average CI \\
\hline Legislators and Senior Officials & 1 & 1 \\
\hline Life Science and Health Professionals & 1 & 1 \\
\hline Teaching Professionals & 1 & 1 \\
\hline Life Science and Health Associate Professionals & 1 & 0.6 \\
\hline Teaching Associate Professionals & 1 & 1 \\
\hline Models, Salespersons and Demonstrators & 1 & 1 \\
\hline Skilled Agricultural and Fishery Workers & 1 & 1 \\
\hline Subsistence Agricultural and Fishery Workers & 1 & 1 \\
\hline Extraction and Building Trades Workers & 1 & 0.6 \\
\hline Precision, Handicraft, Craft Printing and Related Trades Workers & 1 & 1 \\
\hline Other Craft and Related Trades Workers & 1 & 1 \\
\hline Stationary Plant and Related Operators & 1 & 1 \\
\hline Machine Operators and Assemblers & 1 & 1 \\
\hline Agricultural, Fishery and Related Laborers & 1 & 1 \\
\hline Laborers in Mining, Construction, Manufacturing and Transport & 1 & 0.8 \\
\hline Corporate Managers & 0 & 0 \\
\hline Managers of Small Enterprises & 0 & 0 \\
\hline Physical, Mathematical and Engineering Science Professionals & 0 & 0.2 \\
\hline Other Professionals & 0 & 0 \\
\hline Physical and Engineering Associate Professionals & 0 & 0 \\
\hline Other Associate Professionals & 0 & 0 \\
\hline Office Clerks & 0 & 0 \\
\hline Customer Services Clerks & 0 & 0.2 \\
\hline Personal and Protective Services Workers & 0 & 0 \\
\hline Metal, Machinery and Related Trades Workers & 0 & 0.2 \\
\hline Drivers and Mobile Plant Operators & 0 & 0 \\
\hline Sales and Services Elementary Occupations & 0 & 0 \\
\hline
\end{tabular}

Note: This table classifies occupations (2-digit ISCO-88) into specific and general types of human capital according to the value of the average concentration index (CI). An occupation is classified into specific human capital if the value of CI is greater than 0.5 and into general human capital otherwise. 
Table 4: The Share of Specific Human Capital in Industries

\begin{tabular}{lrr}
\hline \hline & & The Share of Specific \\
Industry name & NACE code & Human Capital, \% \\
\hline Fishing & $\mathrm{M}$ & 76.0 \\
Education & $\mathrm{A}$ & 66.7 \\
Agriculture, Hunting and Related Service Activities & $\mathrm{F}$ & 60.8 \\
Construction & $\mathrm{N}$ & 58.1 \\
Health and Social Work & $\mathrm{D}$ & 57.0 \\
Manufacturing & $\mathrm{G}$ & 45.0 \\
Wholesale and Retail Trade; Repair of Motor Vehicles & & 42.7 \\
Motorcycles and Personal and Household Goods & $\mathrm{C}$ & \\
Mining and Quarrying & $\mathrm{E}$ & 40.4 \\
Electricity, Gas and Water Supply & $\mathrm{L}$ & 23.8 \\
Public Administration and Defence; & & 14.5 \\
Compulsory Social Security & $\mathrm{Q}$ & \\
Extra-territorial Organizations and Bodies & $\mathrm{O}$ & 12.3 \\
Other Community, Social and Personal Service Activities & $\mathrm{P}$ & 11.4 \\
Private Households with Employed Persons & $\mathrm{K}$ & 7.7 \\
Real Estate, Renting and Business Activities & $\mathrm{I}$ & 5.9 \\
Transport, Storage and Communication & $\mathrm{H}$ & 3.8 \\
Hotels and Restaurants & $\mathrm{J}$ & 3.4 \\
Financial Intermediation & & 0.6 \\
\hline
\end{tabular}

Note: For each industry this table offers the share of employment in specific human capital occupations out of total industry labor input in terms of the (absolute) number of employees. Industries are ranked from the highest to the lowest intensity in specific human capital. 
Table 5: The Share of Specific Human Capital in Education Fields

\begin{tabular}{lr}
\hline \hline & $\begin{array}{r}\text { The Share of Specific } \\
\text { Education Field }\end{array}$ \\
\hline Health & 79.8 \\
Teacher Training and Educational Science & 75.1 \\
Life Science & 64.0 \\
Manufacturing and Processing & 59.9 \\
Architecture and Building & 53.2 \\
Veterinary & 47.1 \\
Agriculture, Forestry and Fishery & 43.4 \\
Environmental Protection & 36.9 \\
Humanities & 36.6 \\
Arts & 36.1 \\
General Programs & 35.4 \\
Business and Administration & 32.9 \\
Personal Skills & 32.6 \\
Mathematics and Statistics & 31.6 \\
Physical Science & 27.3 \\
Security Services & 26.8 \\
Engineering and Engineering Trades & 23.9 \\
Personal Services & 23.5 \\
Social Services & 16.8 \\
Transport Services & 12.0 \\
Social and Behavioral Science & 9.8 \\
Journalism and Information & 9.3 \\
Computing & 7.5 \\
Law & 7.3 \\
\hline
\end{tabular}

Note: For each education field, this table offers the share of employed individuals who have specific human capital. Education fields are ranked from the highest to the lowest share. The Literacy and Numeracy field is missing from the table because we have virtually no observations for that field in the sample. 
Table 6: Distribution of Skill Levels Across Occupations, \%

\begin{tabular}{|c|c|c|c|}
\hline Occupation Name & $\begin{array}{r}\text { Low-skilled } \\
\text { ISCED }[0-2]\end{array}$ & $\begin{array}{r}\text { Medium-skilled } \\
\text { ISCED }[3-4]\end{array}$ & $\begin{array}{l}\text { Highly Skilled } \\
\text { ISCED [5 - 6] }\end{array}$ \\
\hline Agricultural, Fishery and Related Laborers & 31.2 & 66.7 & 2.1 \\
\hline Sales and Services Elementary Occupations & 29.7 & 69.8 & 0.5 \\
\hline $\begin{array}{l}\text { Laborers in Mining, Construction, } \\
\text { Manufacturing and Transport }\end{array}$ & 25.9 & 73.6 & 0.5 \\
\hline Skilled Agricultural and Fishery Workers & 16.4 & 79.6 & 4 \\
\hline Machine Operators and Assemblers & 12.2 & 87.4 & 0.5 \\
\hline Stationary Plant and Related Operators & 12 & 87.2 & 0.8 \\
\hline Other Craft and Related Trades Workers & 8.8 & 90.6 & 0.6 \\
\hline Drivers and Mobile Plant Operators & 8.3 & 91.1 & 0.5 \\
\hline Models, Salespersons and Demonstrators & 7.7 & 90.8 & 1.5 \\
\hline Personal and Protective Services Workers & 7.2 & 90.3 & 2.5 \\
\hline Military Personnel & 6.3 & 73.4 & 20.3 \\
\hline Office Clerks & 4.7 & 90.6 & 4.7 \\
\hline Customer Services Clerks & 4.6 & 92.6 & 2.9 \\
\hline Extraction and Building Trades Workers & 4.4 & 94.9 & 0.7 \\
\hline $\begin{array}{l}\text { Precision, Handicraft, Craft Printing and } \\
\text { Related Trades Workers }\end{array}$ & 3.7 & 94 & 2.3 \\
\hline Metal, Machinery and Related Trades Workers & 3.7 & 95.6 & 0.7 \\
\hline Managers of Small Enterprises & 2.2 & 67.5 & 30.3 \\
\hline $\begin{array}{l}\text { Physical and Engineering Science } \\
\text { Associate Professionals }\end{array}$ & 1.3 & 82.4 & 16.3 \\
\hline Other Associate Professionals & 1.1 & 80.7 & 18.2 \\
\hline Corporate Managers & 1 & 58.1 & 40.8 \\
\hline Life Science and Health Associate Professionals & 0.2 & 87.8 & 12 \\
\hline Other Professionals & 0.2 & 44.1 & 55.7 \\
\hline Physical, Mathematical and Engineering & 0.1 & 29.6 & 70.3 \\
\hline Science Professionals & 0.1 & 29.6 & 70.3 \\
\hline Legislators and Senior Officials & 0 & 45.7 & 54.3 \\
\hline Life Science and Health Professionals & 0 & 7.6 & 92.4 \\
\hline Teaching Professionals & 0 & 18.3 & 81.7 \\
\hline Teaching Associate Professionals & 0 & 79.2 & 20.8 \\
\hline Subsistence Agricultural and Fishery Workers & 0 & 100 & 0 \\
\hline
\end{tabular}

Note: For each occupation, this table offers the share of employed individuals in each level of highest attained education/skills out of total number of individuals in each occupation. There are three levels of highest attained education: pre-primary to lower-secondary (low-skilled; ISCED-97 0-2), secondary to post-secondary non-tertiary (medium-skilled; ISCED-97 3-4), and tertiary (highly skilled; ISCED-97 5-6). Occupations are listed from the highest to the lowest share of employed individuals who have pre-primary to lower-secondary education (low-skilled; ISCED-97 0-2). The share of employed individuals in each education level can be used as a ranking of occupations according to skill levels. Such a ranking matches surprisingly well with the ranking of the OECD (2010), which we offer in Table (8).

Table 7: Distribution of Skill Levels Across Human Capital Types, \%

\begin{tabular}{lrrr}
\hline \hline & Low-skilled & Medium-skilled & Highly Skilled \\
Human Capital Type & ISCED-97 [0 - 2] & ISCED-97 [3 - 4] & ISCED-97 [5 - 6] \\
\hline Specific & 8.1 & 78.2 & 13.7 \\
General & 4.8 & 79.6 & 15.6 \\
\hline
\end{tabular}

Note: This table offers the share of employed individuals with low-, medium-, and high-level education who have specific human capital occupation out of total employment in specific human capital occupations and the share of employed individuals with low-, medium-, and high-level education who have general human capital occupation out of total employment in general human capital occupations. These levels of education are pre-primary to lower-secondary (low-skilled; ISCED-97 0-2), secondary to post-secondary non-tertiary (medium-skilled; ISCED-97 3-4), and tertiary (highly-skilled; ISCED-97 $5-6)$. 
Table 8: Classification of Occupations into Wider Groups and Skill Levels

\begin{tabular}{|c|c|c|}
\hline Occupation & Wide Group & Skill Level \\
\hline Legislators and Senior Officials & \multirow{2}{*}{\multicolumn{2}{|c|}{$\begin{array}{rr}\text { Highly Skilled and } \\
\text { White Collar }\end{array}$}} \\
\hline Corporate Managers & & \\
\hline Managers of Small Enterprises & & \\
\hline Physical, Mathematical and Engineering & \multirow[t]{4}{*}{2} & \\
\hline Life Science and Health Professionals & & \\
\hline Teaching Professionals & & \\
\hline Other Professionals & & \\
\hline Physical and Engineering Associate Professionals & \multirow[t]{4}{*}{3} & \\
\hline Life Science and Health Associate Professionals & & \\
\hline Teaching Associate Professionals & & \\
\hline Other Associate Professionals & & \\
\hline Office Clerks & \multirow[t]{2}{*}{4} & Low-skilled and \\
\hline Customer Services Clerks & & White Collar \\
\hline Personal and Protective Services Workers & \multirow[t]{2}{*}{5} & \\
\hline Models, Salespersons and Demonstrators & & \\
\hline Skilled Agricultural and Fishery Workers & \multirow[t]{2}{*}{6} & Highly Skilled and \\
\hline Subsistence Agricultural and Fishery Workers & & Blue Collar \\
\hline Extraction and Building Trades Workers & \multirow[t]{5}{*}{7} & \\
\hline Metal, Machinery and Related Trades Workers & & \\
\hline Precision, Handicraft, Craft Printing and & & \\
\hline Related Trades Workers & & \\
\hline Other Craft and Related Trades Workers & & \\
\hline Stationary Plant and Related Operators & \multirow[t]{3}{*}{8} & Low-skilled and \\
\hline Machine Operators and Assemblers & & Blue Collar \\
\hline Drivers and Mobile Plant Operators & & \\
\hline Sales and Services Elementary Occupations & \multirow[t]{4}{*}{9} & \\
\hline Agricultural, Fishery and Related Laborers & & \\
\hline Laborers in Mining, Construction, & & \\
\hline Manufacturing and Transport & & \\
\hline
\end{tabular}

Note: This table offers ISCO-88 classification of occupations into wider occupational groups and the OECD (2010) classification of these occupations into skill levels and types. 
Figure 1: The Employment Share of Specific Human Capital

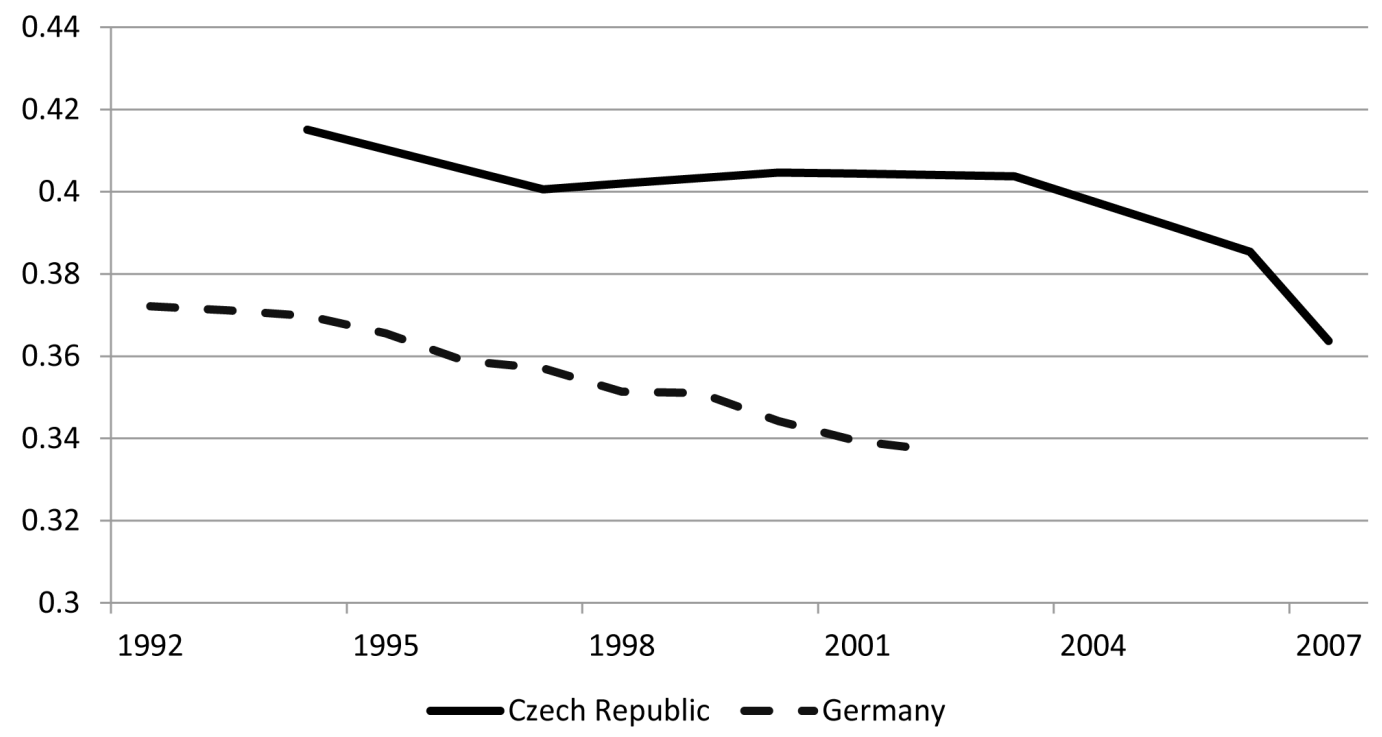

Note: This figure offers the employment share of specific human capital in the Czech Republic (solid line) for the period 1994-2007 and for Germany (dashed line) for the period 1992-2002.

\section{Acknowledgements}

This work is dedicated to the memory of Viatcheslav V. Vinogradov, the author of the original research idea, the project inspiration and the first leader. We would like to thank three anonymous referees, Marek Kapicka, Michal Kejak, Xavier Raurich, Sjak Smulders, Katrin Tinn, and seminar participants at the University of Barcelona and the Armenian Economic Association Meeting in Yerevan (2012) for thoughtful comments. The support of GAAV grant IAA 700850902 is gratefully acknowledged. Vahagn Jerbashian acknowledges the financial support from the Spanish Ministry of Education and Science through grant ECO2012-34046 and the Generalitat of Catalonia through grant 2014SGR493. All errors remaining in this text are the responsibility of the authors.

\section{Notes}

1. Corresponding author: University of Barcelona, Avenue Diagonal 696, Barcelona 08034, Spain. Phone: +34934034890. E-mail: vahagn.jerbashian@ub.edu 
2. CERGE-EI is a joint workplace of the Center for Economic Research and Graduate Education, Charles University in Prague, and the Economics Institute of Academy of Sciences of the Czech Republic.

3. The views expressed in this paper are those of the authors and do not necessarily reflect those of the Bank of Greece.

4. Our definitions of specific and general skills are remotely similar with Becker's definitions in Becker (1962).

5. Acemoglu and Angrist (2000) and Moretti (2003) identify significant and positive human capital externalities. The presence of such externalities implies that in a decentralized equilibrium, returns on human capital are lower than is socially optimal. In our case, it also implies that there is less R\&D than is socially optimal which is in line with, for example, Jones and Williams (1998).

6. The returns from sharing experience/knowledge might be easier to appropriate in a more centralized environment since it can be easy to track the use of shared knowledge in such an environment.

7. The observed trend can also be the net output of a number of different factors apart from those that we highlight in our stylized model, such as structural change or regulatory barriers.

8. More precisely, we compute the coefficient of variation, Herfindahl index, entropy index, exponential index, and Gini index. For each of these concentration measures we create a dummy variable equal to 1 for those values of the concentration measure under consideration that are higher than its median. Our average index is the average of these dummy variables.

9. Using alternative thresholds, like the median or the 30th percentile does not change our 
empirical results materially, even though employing looser definition for classifying occupations as specific human capital naturally increases the total employment rate of the group.

10. The relationship between education and the training of health care professionals could be overstated since they are typically obligated by law to have training in medicine.

11. This excludes military personnel, ISCO-88 0.

12. For the period 1994-2002, the calculation of the specific human capital employment share excludes ISCO-88 62 as the relevant data are not reported in the original source.

13. The downward trend is further confirmed by the European average employment share data by occupation that we obtain from Goos et al. (2010). The average employment share of specific human capital in Europe was 36.3\% in 1993 and decreased to 31.3\% by 2006 . This evidence excludes ISCO- 88 11, 6, 33, 23, 92, as these occupations are not reported. Excluding the same ISCO-88 codes in our data, we find that the Czech Republic moved from an employment share of $34.6 \%$ in 1994 to $31.8 \%$ in 2007.

14. See footnote 7 in Hanushek et al. (2011).

15. Human capital accumulation processes in our model can constitute any type of training.

16. We abstract from any issues of obsolescence and any further labor market frictions in order to highlight the impact of friction in R\&D on human capital allocations.

17. The second term in the right-hand side of expressions (16) and (17) is zero when $\gamma_{3}=0$ because $R \& D$ is a pure externality for the household in this case.

18. The pair $\left(\tau_{Y}^{s}, \tau_{Y}^{g}\right)$ is referred to as education policy in this model given that it affects the household's trade-off between training and working. 
19. This condition holds, for example, for logarithmic instantaneous utility function and/or for sufficiently small $\gamma_{1}$ and sufficiently large $\gamma_{2}$.

20. Similarly, $-g_{q_{2}}$ does not depend on the ratio $\frac{q_{4}}{q_{2}}$ when the allocation of specific human capital to R\&D activity is a (separate) choice variable. In this case the comparative statics can be easily computed (see Appendix 5).

21. These comparative statics also hold when there are several types of specific human capital, some of which do not contribute to R\&D. In this respect, which of these two types of human capital contributes more to $R \& D$ and generates externalities is an interesting empirical question.

22. Clearly, this exercise can underestimate, for example, the required change in $\gamma_{3}$ since in our data there are types of specific human capital which neither engage in training nor in R\&D.

23. The policy $\tau_{Y}^{s}=\tau_{Y}^{g}>0$ represents a subsidy to education to the extent that it increases the return on education relative to the wage rate and motivates schooling.

24. In the current framework, having in mind academia-related $R \& D$ we have assumed that specific human capital which trains specific human capital engages in R\&D. Our findings regarding the benefits from accumulating specific human capital could be biased upwards if general human capital also engages in $R \& D$.

\section{References}

Acemoglu, D. and J. Angrist (2000). How large are human-capital externalities? Evidence from compulsory schooling laws. NBER Macroeconomics Annual 15, 9-59.

Acemoglu, D. and D. H. Autor (2011). Skills, tasks and technologies: Implications for employ- 
ment and earnings. In O. Ashenfelter and D. Card (Eds.), Handbook of Labor Economics, Volume 4b, pp. 1043-1171. North-Holland: Elsevier B.V.

Autor, D. H. and D. Dorn (2013). The growth of low skill service jobs and the polarization of the U.S. labor market. American Economic Review 103(5), 1553-1597.

Becker, G. S. (1962). Investment in human capital: A theoretical analysis. Journal of Political Economy 70(5), 9-49.

Eicher, T. S. (1996). Interaction between endogenous human capital and technological change. Review of Economic Studies 63(1), 127-144.

Goos, M., A. Manning, and A. Salomons (2010). Job polarization in Europe: The roles of technology, globalization and institutions. CEP Discussion Paper No 1026.

Gould, E. D., O. Moav, and B. A. Weinberg (2001). Precautionary demand for education, inequality, and technological progress. Journal of Economic Growth 6(4), 285-315.

Griliches, Z. (1992). The search for R\&D spillovers. Scandinavian Journal of Economics 94, $29-47$.

Hanushek, E. A., L. Wössmann, and L. Zhang (2011). General education, vocational education, and labor-market outcomes over the life-cycle. NBER Working Paper No. 17504.

Hloušek, M. (2012). DSGE model with collateral constraint: estimation on Czech data. In J. Ramík and D. Stavárek (Eds.), Proceedings of 30th International Conference Mathematical Methods in Economics, pp. 296-301. Karviná: Silesian University, School of Business Administration.

Hummels, D., R. Jørgensen, J. Munch, and C. Xiang (2014). The wage effects of offshoring: Evidence from Danish matched worker-firm data. American Economic Review 104(6), 15971629.

Jeong, B., M. Kejak, and V. Vinogradov (2008). Changing composition of human capital: The Czech Republic, Hungary, and Poland. Economics of Transition 16(2), 247-271.

Jones, C. I. and J. C. Williams (1998). Measuring the social return to R\&D. Quarterly Journal 
of Economics 113(4), 1119-1135.

Krueger, D. and K. B. Kumar (2004a). Skill-specific rather than general education: A reason for US-Europe growth differences? Journal of Economic Growth 9(2), 167-207.

Krueger, D. and K. B. Kumar (2004b). US-Europe differences in technology-driven growth: Quantifying the role of education. Journal of Monetary Economics 51(1), 161-190.

Lucas, R. E. (1988). On the mechanics of economic development. Journal of Monetary Economics 22(1), 3-42.

Moretti, E. (2003). Human capital externalities in cities. NBER Working Papers No. 9641.

Nadiri, M. I. (1993). Innovations and technological spillover. NBER Working Papers No. 4423.

OECD (2010). Education at a glance 2010: OECD indicators. Paris, France: OECD.

Romer, P. M. (1990). Endogenous technological change. Journal of Political Economy 98(5), $71-102$.

Sarychev, A. (1999). Dynamic skills acquisition choice-jacks of all trades vs. dab hands. Manuscript, Economics Department, MIT. 


\section{Technical Appendices}

\section{Appendix 1}

From the accumulation processes of the two types of human capital (6) and (7), technology (8) and the expression for physical capital (9) and $\delta(10)$, it follows that on a balanced growth path the growth rates of $H_{s}, H_{g}, K$ and $\Lambda$ are equal:

$$
g_{H_{s}}=g_{H_{g}}=g_{K}=g_{\Lambda} \equiv g .
$$

In turn, from the production function of final goods (1), optimal rules of the representative final goods producer (3), (4), and (5), the budget constraint of the household (12), and the balanced government budget condition (13), it follows that on a balanced growth path the following holds

$$
\begin{aligned}
& g_{Y}=g_{C}=g_{T}=g, \\
& g_{w_{s}}=g_{w_{g}}=g_{r}=0 .
\end{aligned}
$$

Given that all quantities grow at the same rate from (16)-(20), it follows that

$$
g_{q_{1}}=g_{q_{2}}=g_{q_{3}}=g_{q_{4}} \equiv g_{q} .
$$

This expression states that on a balanced growth path the returns on the accumulation of all types of asset holdings are equal.

From (31), (32), and (21) in turn, it follows that

$$
g=\frac{1}{\theta}\left(\lambda_{s}+\lambda_{\Lambda} \gamma_{3} \frac{q_{4}}{q_{2}}-\rho\right) .
$$


The System of Equations that Solves for the Growth Rates and (Relative) Allocations on Balanced Growth Path

From the production function of final goods (1) and the optimal rules of final goods producers (4), (3), and (5), it follows that

$$
\begin{aligned}
\frac{Y}{H_{g}} & =\lambda_{Y}\left[\left(u_{Y}^{s} \frac{H_{s}}{H_{g}}\right)^{\gamma_{2}}\left(\frac{K}{H_{g}}\right)^{1-\gamma_{2}}\right]^{1-\gamma_{1}}, \\
w_{g} & =\gamma_{1} \frac{Y}{H_{g}}
\end{aligned}
$$

$$
\begin{aligned}
& w_{s}=\left(1-\gamma_{1}\right) \gamma_{2} \frac{1}{u_{Y}^{s}} \frac{Y}{H_{s}} \\
& \frac{Y}{r \Lambda}=\frac{1}{\left(1-\gamma_{1}\right)\left(1-\gamma_{2}\right)} .
\end{aligned}
$$

From the accumulation processes of human capitals (6), (7), and ideas (8) and from the expression for physical capital (9), it follows that

$$
\begin{aligned}
& g=\lambda_{s} u_{s}^{s}=\lambda_{g} u_{g}^{s} \frac{H_{s}}{H_{g}}=\lambda_{\Lambda} u_{s}^{s} \frac{H_{s}}{\Lambda}, \\
& \frac{K}{\Lambda}=1 .
\end{aligned}
$$

From the budget constraint (12) and the equation for shares of specific human capital (14), it follows that

$$
\begin{aligned}
& \frac{C}{H_{s}}=\frac{Y}{H_{s}}, \\
& 1=u_{Y}^{s}+u_{s}^{s}+u_{g}^{s} .
\end{aligned}
$$


Finally, from (15) and (32) together with (31), it follows that

$$
g=-\frac{1}{\theta} g_{q},
$$

and

$$
\begin{aligned}
-g_{q} & =\lambda_{s}+\lambda_{\Lambda} \gamma_{3} \frac{q_{4}}{q_{2}}-\rho \\
& =\lambda_{g} \frac{1+\tau_{Y}^{g}}{1+\tau_{Y}^{s}} \frac{\gamma_{1}}{\left(1-\gamma_{1}\right) \gamma_{2}} \frac{H_{s}}{H_{g}} u_{Y}^{s}-\rho \\
& =\frac{1-\gamma_{2}}{\gamma_{2}} \frac{1}{1+\tau_{Y}^{s}} \frac{H_{s}}{\Lambda} u_{Y}^{s}\left(\lambda_{s} \frac{q_{2}}{q_{4}}+\gamma_{3} \lambda_{\Lambda}\right)-\rho .
\end{aligned}
$$

The system of equations (33)-(43) can be solved for balanced growth path (relative) allocations and growth rates.

By elimination this system can be reduced to:

$$
\begin{aligned}
& u_{g}^{s}=\frac{\Gamma_{1} g\left(1-\frac{1}{\lambda_{s}} g\right)}{\left(\theta+\Gamma_{1}\right) g+\rho}, \\
& \theta g=\lambda_{s}+\lambda_{\Lambda} \gamma_{3} \frac{q_{4}}{q_{2}}-\rho, \\
& \left(\theta+\Gamma_{1}\right) g=\Gamma_{2}\left(\lambda_{s} \frac{q_{2}}{q_{4}}+\gamma_{3} \lambda_{\Lambda}\right)\left(1-\frac{1}{\lambda_{s}} g\right)-\rho,
\end{aligned}
$$

where

$$
\begin{aligned}
\Gamma_{1} & =\frac{1+\tau_{Y}^{g}}{1+\tau_{Y}^{s}} \frac{\gamma_{1}}{\left(1-\gamma_{1}\right) \gamma_{2}}, \\
\Gamma_{2} & =\frac{1-\gamma_{2}}{\gamma_{2}} \frac{1}{1+\tau_{Y}^{s}} \frac{\lambda_{s}}{\lambda_{\Lambda}} .
\end{aligned}
$$

From the last two equations of the remaining system $g$ can be eliminated and the resulting equation can be written as

$$
a\left(\frac{q_{4}}{q_{2}}\right)^{2}+b\left(\frac{q_{4}}{q_{2}}\right)+c=0,
$$


where

$$
\begin{aligned}
& a=\left(\theta+\Gamma_{1}+\gamma_{3} \frac{\lambda_{\Lambda}}{\lambda_{s}} \Gamma_{2}\right) \frac{1}{\theta} \lambda_{\Lambda} \gamma_{3}, \\
& b=\frac{\theta+\Gamma_{1}}{\theta}\left(\lambda_{s}-\rho\right)+\rho+\frac{\lambda_{s}(2-\theta)-\rho}{\theta} \gamma_{3} \frac{\lambda_{\Lambda}}{\lambda_{s}} \Gamma_{2}, \\
& c=-\Gamma_{2}\left[\lambda_{s}-\frac{1}{\theta}\left(\lambda_{s}-\rho\right)\right] .
\end{aligned}
$$

Since (49) is a quadratic equation in $\frac{q_{4}}{q_{2}}$, there are two solutions. If $a>0$ and $c<0$, the solutions are real numbers that have different signs. It can be shown that a sufficient condition for this is $\theta \geq 1$.

A similar quadratic equation can be derived for $\frac{H_{s}}{H_{g}}$ using (37) and (44)-(46),

$$
\tilde{a}\left(\frac{H_{s}}{H_{g}}\right)^{2}+\tilde{b}\left(\frac{H_{s}}{H_{g}}\right)+\tilde{c}=0
$$

where

$$
\begin{aligned}
& \tilde{a}=\left[\theta-\frac{1}{\lambda_{s}}\left(\lambda_{s}-\rho\right)\right] \lambda_{g} \Gamma_{1}, \\
& \tilde{b}=-\left[\lambda_{s} \theta+\left(\theta \lambda_{s}+\rho\right) \gamma_{3} \frac{\lambda_{\Lambda}}{\lambda_{s}} \Gamma_{2}+\Gamma_{1}\left(\lambda_{s}-\rho\right)\right], \\
& \tilde{c}=-\frac{1}{\lambda_{g}} \lambda_{s} \rho \gamma_{3} \frac{\lambda_{\Lambda}}{\lambda_{s}} \Gamma_{2} .
\end{aligned}
$$

Similar to the case for $\frac{q_{4}}{q_{2}}$, a sufficient condition for having one real and positive root is $\theta \geq 1$.

\section{Comparative Statics}

From (49), it is straightforward to notice that $\frac{q_{4}}{q_{2}}$ increases with $\rho$, does not depend on $\lambda_{g}$, and is inversely proportional to $\lambda_{\Lambda}$. Moreover, from (49) it can be shown that the sign of the derivative of $\frac{q_{4}}{q_{2}}$ with respect to $\gamma_{1}$ is equivalent to the sign of the following expression: 


$$
\left[-\left(1-\frac{b}{\sqrt{b^{2}-4 a c}}\right) \frac{\partial}{\partial \gamma_{1}} b-\frac{2 c}{\sqrt{b^{2}-4 a c}} \frac{\partial}{\partial \gamma_{1}} a\right] a-\left[-b+\sqrt{b^{2}-4 a c}\right] \frac{\partial}{\partial \gamma_{1}} a .
$$

Since $a>0, \frac{\partial}{\partial \gamma_{1}} b>0$, and $\frac{\partial}{\partial \gamma_{1}} a>0$, it can be easily shown that this expression is negative. Therefore, $\frac{q_{4}}{q_{2}}$ declines with $\gamma_{1}$.

Given that $\frac{q_{4}}{q_{2}}$ does not depend on $\lambda_{g}$ and is inversely proportional to $\lambda_{\Lambda}$, it follows from (37) and (44)-(46) that $\frac{H_{s}}{H_{g}}$ declines with $\lambda_{g}$ and does not depend on $\lambda_{\Lambda}$. In turn, the signs of the derivatives of $\frac{H_{s}}{H_{g}}$ with respect to $\gamma_{1}$ and $\theta$ are equivalent to the signs of the following expressions.

$$
\begin{aligned}
& -\tilde{a} \frac{\partial}{\partial \theta} \tilde{b}+\tilde{b} \frac{\partial}{\partial \theta} \tilde{a}+\frac{2 \tilde{a} \tilde{c}}{\sqrt{\tilde{b}^{2}-4 \tilde{a} \tilde{c}}-\tilde{b}} \frac{\partial}{\partial \theta} \tilde{a} \\
& -\tilde{a} \frac{\partial}{\partial \gamma_{1}} \tilde{b}+\tilde{b} \frac{\partial}{\partial \gamma_{1}} \tilde{a}+\frac{2 \tilde{a} \tilde{c}}{\sqrt{\tilde{b}^{2}-4 \tilde{a} \tilde{c}}-\tilde{b}} \frac{\partial}{\partial \gamma_{1}} \tilde{a} .
\end{aligned}
$$

These expressions are negative since $\tilde{c}<0, \tilde{a} \frac{\partial}{\partial \theta} \tilde{b}>\tilde{b} \frac{\partial}{\partial \theta} \tilde{a}$, and $\tilde{a} \frac{\partial}{\partial \gamma_{1}} \tilde{b}>\tilde{b} \frac{\partial}{\partial \gamma_{1}} \tilde{a}$. Therefore, $\frac{H_{s}}{H_{g}}$ declines with $\gamma_{1}$ and $\theta$.

Meanwhile, since

$$
\begin{aligned}
& \frac{\partial}{\partial \gamma_{3}} \tilde{b}<0, \\
& \frac{\partial}{\partial \gamma_{3}} \tilde{c}<0, \\
& \frac{\partial}{\partial \gamma_{3}} \tilde{a}=0, \\
& \frac{\partial}{\partial \lambda_{s}} \tilde{b}<0, \\
& \frac{\partial}{\partial \lambda_{s}}(\tilde{a} \tilde{c})<0, \\
& \frac{\partial}{\partial \lambda_{s}} \tilde{a}<0,
\end{aligned}
$$


from (50) it follows that $\frac{H_{s}}{H_{g}}$ increases with $\gamma_{3}$ and $\lambda_{s}$.

When $\tau_{Y}^{g} \equiv \tau_{Y}^{s}$, it can be shown that the following holds

$$
\frac{\partial}{\partial \tau_{Y}^{s}} \tilde{b}, \frac{\partial}{\partial \tau_{Y}^{s}} \tilde{c}<0 ; \frac{\partial}{\partial \tau_{Y}^{s}} \tilde{a}=0
$$

It follows then from (50) that in this case $\frac{H_{s}}{H_{g}}$ declines with $\tau_{Y}^{s}$. According to (37), the ratio of specific human capital to physical human capital $\frac{H_{s}}{\Lambda}$ depends only on $\lambda_{s}$ and $\lambda_{\Lambda}$. It increases with $\lambda_{s}$ and declines with $\lambda_{\Lambda}$.

Table 9 summarizes the signs of comparative statics that follow from these results together with (37) and (44)-(46). Deriving the signs of the remaining comparative statics requires tedious algebra. Numerical methods are used in order to obtain them. These additional results, together with the intervals of parameter values used in the numerical exercises, are presented in Table 1.

\section{Appendix 2}

Denote

$$
\begin{gathered}
\omega_{1}=\frac{H_{g}}{H_{s}}, \\
\omega_{2}=\frac{\Lambda}{H_{s}} .
\end{gathered}
$$

In the case of an interior solution for the shares of specific human capital [i.e., $u_{s}^{s}, u_{g}^{s}, u_{Y}^{s} \in(0,1)$ ], it can be shown that the dynamic system of equations of the model reduces to two differential equations from $u_{Y}^{s}$ and $\omega_{2}$. These equations are

$$
\left(\begin{array}{c}
g_{u_{Y}^{s}} \\
g_{\omega_{2}}
\end{array}\right)=\frac{1}{\operatorname{det} A\left(u_{Y}^{s}, \omega_{2}\right)}\left(\begin{array}{c}
A_{22} b_{1}-A_{12} b_{2} \\
A_{11} b_{2}-A_{21} b_{1}
\end{array}\right)
$$


where

$$
\begin{aligned}
& \operatorname{det} A\left(u_{Y}^{s}, \omega_{2}\right)=A_{11} A_{22}-A_{12} A_{21}, \\
& A_{11}=\frac{\lambda_{\Lambda}-\lambda_{s} \omega_{2}}{\omega_{2}} \frac{1}{\lambda_{g}} \frac{\frac{\lambda_{g}}{\lambda_{s}} \Gamma_{1} u_{Y}^{s}}{1+\gamma_{3} \frac{\lambda_{\Lambda}}{\lambda_{s}} \frac{\lambda_{\Lambda}}{\lambda_{s}} \Gamma_{2} \frac{1}{\omega_{2}} u_{Y}^{s}} \frac{1}{1+\gamma_{3} \frac{\lambda_{\Lambda}}{\lambda_{s}} \frac{\lambda_{\Lambda}}{\lambda_{s}} \Gamma_{2} \frac{1}{\omega_{2}} u_{Y}^{s}}, \\
& A_{12}=1+\frac{\Gamma_{1} u_{Y}^{s}}{1+\gamma_{3} \frac{\lambda_{\Lambda}}{\lambda_{s}} \frac{\lambda_{\Lambda}}{\lambda_{s}} \Gamma_{2} \frac{1}{\omega_{2}} u_{Y}^{s}}+\gamma_{3} \frac{\lambda_{\Lambda}}{\lambda_{s}} \frac{\lambda_{\Lambda}}{\lambda_{s}} \Gamma_{2} \frac{1}{\omega_{2}} u_{Y}^{s} A_{11}, \\
& A_{21}=\frac{\lambda_{\Lambda}-\lambda_{s} \omega_{2}}{\omega_{2}}\left[1+(\theta-1)\left(1-\gamma_{1}\right) \gamma_{2}+(\theta-1) \gamma_{1} \frac{1}{1+\gamma_{3} \frac{\lambda_{\Lambda}}{\lambda_{s}} \frac{\lambda_{\Lambda}}{\lambda_{s}} \Gamma_{2} \frac{1}{\omega_{2}} u_{Y}^{s}}\right], \\
& A_{22}=\theta \frac{\lambda_{\Lambda}}{\omega_{2}}-A_{21}, \\
& b_{1}=\frac{\lambda_{\Lambda}-\lambda_{s} \omega_{2}}{\omega_{2}}\left(1-u_{Y}^{s}\right), \\
& b_{2}=\frac{\lambda_{\Lambda}-\lambda_{s} \omega_{2}}{\omega_{2}}\left[\lambda_{s}\left(1+\gamma_{3} \frac{\lambda_{\Lambda}}{\lambda_{s}} \frac{\lambda_{\Lambda}}{\lambda_{s}} \Gamma_{2} \frac{1}{\omega_{2}} u_{Y}^{s}\right)-\rho\right] .
\end{aligned}
$$

Therefore, the Jacobian of the system is a two-by-two matrix, and its elements are

$$
\begin{aligned}
J(1,1) & =\frac{1}{\operatorname{det} A\left(u_{Y}^{s}, \omega_{2}\right)} \frac{\partial}{\partial u_{Y}^{s}}\left(A_{22} b_{1}-A_{12} b_{2}\right) \\
& -\left[\frac{1}{\operatorname{det} A\left(u_{Y}^{s}, \omega_{2}\right)}\right]^{2}\left(A_{22} b_{1}-A_{12} b_{2}\right) \frac{\partial}{\partial u_{Y}^{s}} \operatorname{det} A\left(u_{Y}^{s}, \omega_{2}\right), \\
J(1,2) & =\frac{1}{\operatorname{det} A\left(u_{Y}^{s}, \omega_{2}\right)} \frac{\partial}{\partial \omega_{2}}\left(A_{22} b_{1}-A_{12} b_{2}\right) \\
& -\left[\frac{1}{\operatorname{det} A\left(u_{Y}^{s}, \omega_{2}\right)}\right]^{2}\left(A_{22} b_{1}-A_{12} b_{2}\right) \frac{\partial}{\partial \omega_{2}} \operatorname{det} A\left(u_{Y}^{s}, \omega_{2}\right), \\
J(2,1) & =\frac{1}{\operatorname{det} A\left(u_{Y}^{s}, \omega_{2}\right)} \frac{\partial}{\partial u_{Y}^{s}}\left(A_{11} b_{2}-A_{21} b_{1}\right) \\
& -\left[\frac{1}{\operatorname{det} A\left(u_{Y}^{s}, \omega_{2}\right)}\right]^{2}\left(A_{11} b_{2}-A_{21} b_{1}\right) \frac{\partial}{\partial u_{Y}^{s}} \operatorname{det} A\left(u_{Y}^{s}, \omega_{2}\right),
\end{aligned}
$$

and

$$
\begin{aligned}
J(2,2) & =\frac{1}{\operatorname{det} A\left(u_{Y}^{s}, \omega_{2}\right)} \frac{\partial}{\partial \omega_{2}}\left(A_{11} b_{2}-A_{21} b_{1}\right) \\
& -\left[\frac{1}{\operatorname{det} A\left(u_{Y}^{s}, \omega_{2}\right)}\right]^{2}\left(A_{11} b_{2}-A_{21} b_{1}\right) \frac{\partial}{\partial \omega_{2}} \operatorname{det} A\left(u_{Y}^{s}, \omega_{2}\right)
\end{aligned}
$$


It is straightforward to notice that $\operatorname{det} A\left(u_{Y}^{s}, \omega_{2}\right)$ is proportional to $\frac{\lambda_{\Lambda}-\lambda_{s} \omega_{2}}{\omega_{2}}$. In turn, $\left(A_{11} b_{2}-A_{21} b_{1}\right)$ is proportional to the square of $\frac{\lambda_{\Lambda}-\lambda_{s} \omega_{2}}{\omega_{2}}$. At the steady-state (balanced growth path), where

$$
\begin{aligned}
& u_{Y}^{s}=1-\frac{\Gamma_{1}\left(1-\frac{g}{\lambda_{s}}\right)}{\left(\theta+\Gamma_{1}\right) g+\rho} g-\frac{1}{\lambda_{s}} g, \\
& \omega_{2}=\frac{\lambda_{\Lambda}}{\lambda_{s}}, \\
& \left(\begin{array}{c}
0 \\
0
\end{array}\right)=\frac{1}{\operatorname{det} A}\left(\begin{array}{c}
A_{22} b_{1}-A_{12} b_{2} \\
A_{11} b_{2}-A_{21} b_{1}
\end{array}\right),
\end{aligned}
$$

this implies that

$$
\frac{\partial}{\partial u_{Y}^{s}} g_{\omega_{2}}=0
$$

Therefore, the eigenvalues of the Jacobian matrix at the steady-state are $J(1,1)$ and $J(2,2)$.

After some tedious algebra, it can be shown that at the steady-state

$$
J(2,2)<0
$$

and $J(1,1)$ is positive if the determinant of matrix $A$ is negative. The determinant of matrix $A$ is negative if

$$
\begin{aligned}
& \left\{(\theta-1)\left(1-\gamma_{1}\right)\left(1-\gamma_{2}\right)-\gamma_{3} \frac{\lambda_{\Lambda}}{\lambda_{s}} \Gamma_{2}\left[1+(\theta-1)\left(1-\gamma_{1}\right) \gamma_{2}\right] u_{Y}^{s}\right\} \Gamma_{1} u_{Y}^{s} \\
& -\left(1+\gamma_{3} \frac{\lambda_{\Lambda}}{\lambda_{s}} \Gamma_{2} u_{Y}^{s}\right)\left\{\left[1+(\theta-1)\left(1-\gamma_{1}\right) \gamma_{2}\right]\left(1+\gamma_{3} \frac{\lambda_{\Lambda}}{\lambda_{s}} \Gamma_{2} u_{Y}^{s}\right)+(\theta-1) \gamma_{1}\right\} \\
& <0
\end{aligned}
$$

where $u_{Y}^{s}$ is given by (37) and (40). 
Since $u_{Y}^{s} \in(0,1)$ a sufficient condition for saddle path stability is

$$
\left[\left(1-\gamma_{2}\right) \frac{\gamma_{1}}{\gamma_{2}} \frac{1+\tau_{Y}^{g}}{1+\tau_{Y}^{s}}-\left(1-\gamma_{1}\right) \gamma_{2}-\gamma_{1}\right]<\frac{1}{\theta-1}
$$

When tax rates $\tau_{Y}^{s}$ and $\tau_{Y}^{g}$ are equated, this condition can be rewritten as

$$
\left(1-\gamma_{2}\right)^{2} \frac{\gamma_{1}}{\gamma_{2}}-\gamma_{2}<\frac{1}{\theta-1}
$$

and holds, for example, for $\gamma_{2}>0.5$ or for $\theta=1$.

If the initial value of the ratio of human capital types, $\omega_{2}$, is not at its steady-state, the model exhibits transition dynamics along the stable manifold. At time 0 , the value of $u_{Y}^{s}$ jumps to the stable-manifold level, after which a monotonic convergence of $u_{Y}^{s}, \omega_{2}$, as well as $\omega_{1}$ to their steady-state values is observed. Figure 2 presents the stable manifold in $\left(u_{Y}^{s}, \omega_{2}\right)$ space for the following parameter values:

$$
\begin{aligned}
& \rho=0.05, \theta=1, \gamma_{1}=0.39, \gamma_{2}=0.51, \gamma_{3}=0.9, \\
& \lambda_{s}=0.1, \lambda_{g}=0.67, \lambda_{\Lambda}=0.1, \tau_{Y}^{s}=\tau_{Y}^{g} .
\end{aligned}
$$

It might happen that the initial value of general human capital is such that either $u_{s}^{s}$ or $u_{g}^{s}$ hits zero bound. ${ }^{1}$

For example, suppose that $u_{s}^{s}>0$ and $u_{g}^{s}=0$. In this case,

$$
\lambda_{g} q_{3}<\lambda_{s} q_{2}+\gamma_{3} \lambda_{\Lambda} q_{4}
$$

Since the wage of general human capital, $w_{g}$, increases relative to the wage of specific human capital, $w_{s}$, and the return on physical capital, $r$, as $H_{s}$ and $K$ grow, at some point in time $w_{g}$

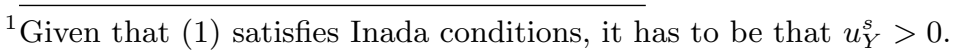


will become so large that $u_{g}^{s}$ will become positive. This is equivalent to a declining $q_{2}$ and $q_{4}$ and a constant $q_{3}$ in (53) and can hold if the economy is relatively abundant in general human capital. Such a situation holds, for example, when $\omega_{1} \geq 1, \theta=5$, and the remaining parameters are given by (52).

Similarly, when $u_{s}^{s}=0$ and $u_{g}^{s}>0$ then the following holds

$$
\lambda_{g} q_{3}>\lambda_{s} q_{2}+\gamma_{3} \lambda_{\Lambda} q_{4}
$$

In this case, since $w_{s}$ and $r$ increase relative to $w_{g}$ as $H_{g}$ grows at some point in time, $u_{s}^{s}$ will become positive. This is equivalent to a declining $q_{3}$ and a constant $q_{2}$ and $q_{4}$ in (54) and can hold if the economy is relatively abundant in specific human capital. Such a situation holds, for example, when $\omega_{1} \leq 0.2$ and for parameter values (52).

\section{Appendix 3}

It can be shown that in the social optimum, the quadratic equation (49) is given by

$$
\begin{aligned}
& \left(\frac{\theta+\tilde{\Gamma}_{1}}{\theta}+\tilde{\Gamma}_{2} \frac{\lambda_{\Lambda}}{\lambda_{s}} \frac{1}{\theta}\right) \lambda_{\Lambda}\left(\frac{q_{4}}{q_{2}}\right)^{2}+ \\
& +\left[\frac{\theta+\tilde{\Gamma}_{1}}{\theta}\left(\lambda_{s}-\rho\right)+\rho+\frac{\lambda_{s}(1-\theta)+\lambda_{s}-\rho}{\lambda_{s} \theta} \tilde{\Gamma}_{2} \lambda_{\Lambda}\right] \frac{q_{4}}{q_{2}}- \\
& -\tilde{\Gamma}_{2}\left[\lambda_{s}-\frac{1}{\theta}\left(\lambda_{s}-\rho\right)\right]=0,
\end{aligned}
$$

where $\tilde{\Gamma}_{1}$ and $\tilde{\Gamma}_{2}$ are given by (47) and (48) with the tax rates $\tau_{Y}^{s}$ and $\tau_{Y}^{g}$ set to zero. This implies that when the tax rates in the decentralized equilibrium are set so that

$$
\begin{aligned}
& 1+\tau_{Y}^{s}=\gamma_{3}, \\
& 1+\tau_{Y}^{g}=1+\tau_{Y}^{s},
\end{aligned}
$$


(thus making $\tilde{\Gamma}_{1}=\Gamma_{1}$ and $\tilde{\Gamma}_{2}=\gamma_{3} \Gamma_{2}$ ), the positive root of (55) coincides with $\gamma_{3}$ times the positive root of (49). In other words,

$$
\gamma_{3} \frac{q_{4}}{q_{2}}=\left(\frac{q_{4}}{q_{2}}\right)^{S P}
$$

where SP denotes the social planner's solution.

Moreover, it can be easily shown that the system of equations which solves for the balanced growth path allocations and growth rates of social optimum is essentially the same as (33)-(43), except that $\gamma_{3}$ is equal to 1 in (43). Therefore, it can be shown that the policy (56) and (57) delivers socially optimal allocations and growth rates in the decentralized equilibrium on the balanced growth path. According to (51), it also does so on the transition path.

\section{Appendix 4}

In this section, we offer the decentralized equilibrium results when $\gamma_{3}=0$.

The problem and optimal decision rules of the final goods producer and the human capital accumulation processes remain the same. Therefore, the expressions (1)-(7) are still valid. When $\gamma_{3}=0$, the accumulation of technology is a pure externality for the household. Therefore, the household's problem is

$$
\begin{aligned}
& \max _{u_{Y}^{s}, u_{g}^{s}, C}\left\{\int_{0}^{+\infty} \frac{C_{t}^{1-\theta}-1}{1-\theta} \exp (-\rho t) d t\right\} \\
& \text { s.t. } \\
& (12),(6),(7),(14), \\
& H_{s}(0), H_{g}(0), K(0)>0-\text { given. }
\end{aligned}
$$

Assigning shadow values $\left\{q_{i}\right\}$ to constraints (12), (6), (7), the decision rules that follow from 
the household's optimization are

$$
\begin{aligned}
& C^{-\theta}=q_{1}, \\
& q_{1} w_{s}\left(1+\tau_{Y}^{s}\right) H_{s}=q_{2} \frac{\dot{H}_{s}}{u_{s}^{s}}, \\
& q_{3} \frac{\dot{H}_{g}}{u_{g}^{s}}=q_{2} \frac{\dot{H}_{s}}{u_{s}^{s}}, \\
& q_{1} r>0 \Rightarrow \text { supply all } K, \\
& \dot{q}_{2}=q_{2} \rho-\left[q_{1} w_{s} u_{Y}^{s}\left(1+\tau_{Y}^{s}\right)+q_{2} \frac{\dot{H}_{s}}{H_{s}}+q_{3} \frac{\dot{H}_{g}}{H_{s}}\right], \\
& \dot{q}_{3}=q_{3} \rho-q_{1} w_{g}\left(1+\tau_{Y}^{g}\right) .
\end{aligned}
$$

From (6), (7), (59), (60), (61), and (62), it follows that

$$
\begin{aligned}
& \frac{q_{3}}{q_{2}}=\frac{\lambda_{s}}{\lambda_{g}}, \\
& -g_{q_{2}}=\lambda_{s}-\rho, \\
& -g_{q_{3}}=\lambda_{g} \frac{w_{g}\left(1+\tau_{Y}^{g}\right)}{w_{s}\left(1+\tau_{Y}^{s}\right)}-\rho .
\end{aligned}
$$

This implies that when both types of human capital are accumulated, the ratio of wages should be fixed

$$
\frac{w_{g}\left(1+\tau_{Y}^{g}\right)}{w_{s}\left(1+\tau_{Y}^{s}\right)}=\frac{\lambda_{s}}{\lambda_{g}} .
$$

The economy is on a balanced growth path in such a case. The growth rate of the economy (quantities) on a balanced growth path is

$$
g=\frac{1}{\theta}\left(\lambda_{s}-\rho\right) .
$$

The growth rate above is less than the socially optimal one, given by the equation (26) with $\gamma_{3}$ set to one. Therefore, the share of the specific human capital allocated to its accumulation 
is lower than its socially optimal value, because $u_{s}^{s}$ is proportional to the growth rate of $H_{s}$ and all the quantities are growing at the same rate.

The comparative statics for this model can be derived analytically and are presented in Table 10. For example, $u_{g}^{s}$ increases with $\rho$ and $\theta$ when $\theta=1$ and $\lambda_{s}>2 \rho$ and declines with these parameters when $\theta>>1$. Meanwhile, $u_{g}^{s}$ increases with $\lambda_{s}$ when $\theta>>1$ and $\lambda_{s}<2 \rho$ and declines when $\lambda_{s}>2 \rho$.

\section{Appendix 5}

In this section, we offer the decentralized equilibrium results when $R \& D$ intensity is a choice variable.

Similarly to Appendix 4, the problem and optimal decision rules of the final goods producer and the human capital accumulation processes remain the same. Therefore, the expressions (1)(7) are still valid. However, the R\&D equation and the equation for shares of specific human capital change. The household's problem in such a case is

$$
\begin{aligned}
& \max _{u_{Y}^{s}, u_{g}^{s}, C}\left\{\int_{0}^{+\infty} \frac{C_{t}^{1-\theta}-1}{1-\theta} \exp (-\rho t) d t\right\} \\
& \text { s.t. } \\
& (12),(6),(7), \\
& \dot{\Lambda}=\delta\left(u_{\Lambda}^{s} H_{s}\right)^{\gamma_{3}} \\
& u_{s}^{s}+u_{Y}^{s}+u_{g}^{s}+u_{\Lambda}^{s} \leq 1, \\
& H_{s}(0), H_{g}(0), \Lambda(0)>0-\text { given. }
\end{aligned}
$$

Assigning shadow value $\left\{q_{i}\right\}$ to constraints (12), (6), (7), and (63), the decision rules that follow 
from the household's optimization are

$$
\begin{aligned}
& C^{-\theta}=q_{1}, \\
& q_{1} w_{s}\left(1+\tau_{Y}^{s}\right) H_{s}=q_{2} \frac{\dot{H}_{s}}{u_{s}^{s}}, \\
& q_{3} \frac{\dot{H}_{g}}{u_{g}^{s}}=q_{2} \frac{\dot{H}_{s}}{u_{s}^{s}}, \\
& q_{4} \gamma_{3} \frac{\dot{\Lambda}}{u_{\Lambda}^{s}}=q_{2} \frac{\dot{H}_{s}}{u_{s}^{s}}, \\
& \dot{q}_{2}=q_{2} \rho-\left[q_{1} w_{s} u_{Y}^{s}\left(1+\tau_{Y}^{s}\right)+q_{2} \frac{\dot{H}_{s}}{H_{s}}+q_{3} \frac{\dot{H}_{g}}{H_{s}}+q_{4} \gamma_{3} \frac{\dot{\Lambda}}{H_{s}}\right], \\
& \dot{q}_{3}=q_{3} \rho-q_{1} w_{g}\left(1+\tau_{Y}^{g}\right), \\
& \dot{q}_{4}=q_{4} \rho-q_{1} r k .
\end{aligned}
$$

These optimal rules imply that

$$
\begin{aligned}
& \frac{q_{3}}{q_{2}}=\frac{\lambda_{s}}{\lambda_{g}}, \\
& \frac{q_{4}}{q_{2}}=\frac{\lambda_{s}}{\gamma_{3} \lambda_{\Lambda}}, \\
& -g_{q_{2}}=\lambda_{s}-\rho,
\end{aligned}
$$

and

$$
\begin{aligned}
& -g_{q_{3}}=\lambda_{g} \frac{w_{g}\left(1+\tau_{Y}^{g}\right)}{w_{s}\left(1+\tau_{Y}^{s}\right)}-\rho, \\
& -g_{q_{4}}=\gamma_{3} \lambda_{\Lambda} \frac{r k}{w_{s}\left(1+\tau_{Y}^{s}\right)}-\rho .
\end{aligned}
$$

Therefore, on a balanced growth path the growth rate of the economy and the share of specific 
human capital allocation to its accumulation are

$$
\begin{aligned}
& g=\frac{1}{\theta}\left(\lambda_{s}-\rho\right), \\
& u_{s}^{s}=\frac{g}{\lambda_{s}} .
\end{aligned}
$$

The comparative statics for this model can be derived analytically and are presented in Table 11. When $\theta>>1, \frac{\partial}{\partial \lambda_{s}} u_{g}^{s}$ and $\frac{\partial}{\partial \lambda_{s}} u_{\Lambda}^{s}$ are both positive; these derivatives become negative when $\theta=1$ and $\gamma_{2} \approx 0$ or $\gamma_{1} \approx 1$. When $\theta>>1, \frac{\partial}{\partial \rho} u_{g}^{s}$ and $\frac{\partial}{\partial \rho} u_{\Lambda}^{s}$ are negative but turn positive for $\gamma_{2} \approx 0$ or $\gamma_{1} \approx 1$. Finally, $\frac{\partial}{\partial \theta} u_{g}^{s}$ and $\frac{\partial}{\partial \theta} u_{\Lambda}^{s}$ are negative when $\theta>>1$, but these derivatives change sign for $\gamma_{2} \approx 0$ or $\gamma_{1} \approx 1$.

\section{Appendix 6}

In this section, we analyze the decentralized equilibrium of a version of the model where we include physical capital and general human capital in the education and R\&D processes. To guarantee the existence of the balanced growth path, we assume that education and R\&D processes are given by

$$
\begin{aligned}
& \dot{H}_{s}=\lambda_{s}\left(u_{s}^{g} H_{g}\right)^{\gamma_{1}^{s}}\left[\left(u_{s}^{s} H_{s}\right)^{\gamma_{2}^{s}}\left(u_{s}^{K} K\right)^{1-\gamma_{2}^{s}}\right]^{1-\gamma_{1}^{s}}, \\
& \dot{H}_{g}=\lambda_{g}\left(u_{g}^{g} H_{g}\right)^{\gamma_{1}^{g}}\left[\left(u_{g}^{s} H_{s}\right)^{\gamma_{2}^{g}}\left(u_{g}^{K} K\right)^{1-\gamma_{2}^{g}}\right]^{1-\gamma_{1}^{g}}, \\
& \dot{\Lambda}=\delta\left[\left(u_{s}^{g} H_{g}\right)^{\gamma_{1}^{\Lambda}}\left(u_{s}^{s} H_{s}\right)^{1-\gamma_{1}^{\Lambda}}\right]^{\gamma_{3}},
\end{aligned}
$$

where $\gamma_{1}^{s}, \gamma_{1}^{g}, 1-\gamma_{2}^{s}, 1-\gamma_{2}^{g} \in[0,1)$ are the exponents of general human capital and physical capital in the education processes. $\gamma_{1}^{\Lambda} \in[0,1)$ is the exponent of general human capital in the R\&D process. $\delta$ measures external effects. We assume that, in equilibrium, $\delta$ is given by

$$
\delta=\lambda_{\Lambda}\left[\left(u_{s}^{g} H_{g}\right)^{\gamma_{1}^{\Lambda}}\left(u_{s}^{s} H_{s}\right)^{1-\gamma_{1}^{\Lambda}}\right]^{1-\gamma_{3}} .
$$


Moreover, we assume that now the production function of final goods is given by

$$
Y=\lambda_{Y}\left(u_{Y}^{g} H_{g}\right)^{\gamma_{1}}\left[\left(u_{Y}^{s} H_{s}\right)^{\gamma_{2}}\left(u_{Y}^{K} K\right)^{1-\gamma_{2}}\right]^{1-\gamma_{1}}
$$

where we use letter $u$ to denote shares,

$$
\begin{aligned}
& u_{Y}^{s}+u_{s}^{s}+u_{g}^{s}=1, \\
& u_{Y}^{g}+u_{s}^{g}+u_{g}^{g}=1, \\
& u_{Y}^{K}+u_{s}^{K}+u_{g}^{K}=1 .
\end{aligned}
$$

The remainder of the model remains the same.

It can be shown that the first order conditions from the firm's problem are given by

$$
\begin{aligned}
& w_{g} u_{Y}^{g} H_{g}=\gamma_{1} Y, \\
& w_{s} u_{Y}^{s} H_{s}=\left(1-\gamma_{1}\right) \gamma_{2} Y, \\
& r u_{Y}^{K} K=\left(1-\gamma_{1}\right)\left(1-\gamma_{2}\right) Y .
\end{aligned}
$$


The first order conditions from the household's problem are given by

$$
\begin{aligned}
& C^{-\theta}=q_{1}, \\
& q_{1} w_{s}\left(1+\tau_{Y}^{s}\right) H_{s}=q_{2}\left(1-\gamma_{1}^{s}\right) \gamma_{2}^{s} \frac{\dot{H}_{s}}{u_{s}^{s}}+q_{4} \gamma_{3}\left(1-\gamma_{1}^{\Lambda}\right) \frac{\dot{\Lambda}}{u_{s}^{s}}, \\
& q_{3}\left(1-\gamma_{1}^{g}\right) \gamma_{2}^{s} \frac{\dot{H}_{g}}{u_{g}^{s}}=q_{2}\left(1-\gamma_{1}^{s}\right) \gamma_{2}^{s} \frac{\dot{H}_{s}}{u_{s}^{s}}+q_{4} \gamma_{3}\left(1-\gamma_{1}^{\Lambda}\right) \frac{\dot{\Lambda}}{u_{s}^{s}}, \\
& q_{1} w_{g}\left(1+\tau_{Y}^{g}\right) H_{g}=q_{2} \gamma_{1}^{s} \frac{\dot{H}_{s}}{u_{s}^{g}}+q_{4} \gamma_{3} \gamma_{1}^{\Lambda} \frac{\dot{\Lambda}}{u_{s}^{g}}, \\
& q_{3} \gamma_{1}^{g} \frac{\dot{H}_{g}}{u_{g}^{g}}=q_{2} \gamma_{1}^{s} \frac{\dot{H}_{s}}{u_{s}^{g}}+q_{4} \gamma_{3} \gamma_{1}^{\Lambda} \frac{\dot{\Lambda}}{u_{s}^{g}}, \\
& q_{1} r K=q_{2}\left(1-\gamma_{1}^{s}\right)\left(1-\gamma_{2}^{s}\right) \frac{\dot{H}_{s}}{u_{s}^{K}}, \\
& q_{3}\left(1-\gamma_{1}^{g}\right)\left(1-\gamma_{2}^{g}\right) \frac{\dot{H}_{g}}{u_{g}^{K}}=q_{2}\left(1-\gamma_{1}^{s}\right)\left(1-\gamma_{2}^{s}\right) \frac{\dot{H}_{s}}{u_{s}^{K}} .
\end{aligned}
$$

In turn, the envelope theorem conditions from the household's problem are given by

$$
\begin{aligned}
& \dot{q}_{2}=q_{2} \rho-\left[q_{1} w_{s} u_{Y}^{s}\left(1+\tau_{Y}^{s}\right)+q_{2}\left(1-\gamma_{1}^{s}\right) \gamma_{2}^{s} \frac{\dot{H}_{s}}{H_{s}}+q_{3}\left(1-\gamma_{1}^{g}\right) \gamma_{2}^{g} \frac{\dot{H}_{g}}{H_{s}}\right. \\
& \left.+q_{4} \gamma_{3}\left(1-\gamma_{1}^{\Lambda}\right) \frac{\dot{\Lambda}}{H_{s}}\right], \\
& \dot{q}_{3}=q_{3} \rho-\left[q_{1} w_{g} u_{Y}^{g}\left(1+\tau_{Y}^{g}\right)+q_{2} \gamma_{1}^{s} \frac{\dot{H}_{s}}{H_{g}}+q_{3} \gamma_{1}^{g} \frac{\dot{H}_{g}}{H_{g}}+q_{4} \gamma_{3} \gamma_{1}^{\Lambda} \frac{\dot{\Lambda}}{H_{g}}\right], \\
& \dot{q}_{4}=q_{4} \rho-\left[q_{1} r u_{Y}^{K} k+q_{2}\left(1-\gamma_{1}^{s}\right)\left(1-\gamma_{2}^{s}\right) \frac{\dot{H}_{s}}{K}+q_{3}\left(1-\gamma_{1}^{g}\right)\left(1-\gamma_{2}^{g}\right) \frac{\dot{H}_{g}}{K}\right] .
\end{aligned}
$$

Denoting $u_{g, \gamma}^{g}=\frac{1}{\gamma_{1}^{g}} u_{g}^{g}$ and $x=\frac{q_{4}}{q_{2}} \frac{\Lambda}{H_{s}}$, the system of equations which characterizes equilibrium allocations on the balanced growth path can be written as

$$
\begin{aligned}
& u_{s}^{s}=\left[\left(1-\gamma_{1}^{s}\right) \gamma_{2}^{s}+\gamma_{3}\left(1-\gamma_{1}^{\Lambda}\right) x\right] u_{g, \gamma}^{g}, \\
& u_{s}^{g}=\left(1-\gamma_{1}^{g}\right) \gamma_{2}^{s} \frac{\gamma_{1}^{s}+\gamma_{3} \gamma_{1}^{\Lambda} x}{\left(1-\gamma_{1}^{s}\right) \gamma_{2}^{s}+\gamma_{3}\left(1-\gamma_{1}^{\Lambda}\right) x} \frac{u_{g, \gamma}^{g}}{u_{g}^{s}} u_{s}^{s}, \\
& g=\frac{1}{\theta}\left(\frac{1}{u_{g, \gamma}^{g}} g-\rho\right),
\end{aligned}
$$


and

$$
\begin{aligned}
& g=\lambda_{s}\left(u_{s}^{g} \frac{H_{g}}{H_{s}}\right)^{\gamma_{1}^{s}}\left\{\left(u_{s}^{s}\right)^{\gamma_{2}^{s}}\left[\left(1-\gamma_{1}^{s}\right)\left(1-\gamma_{2}^{s}\right) \frac{1}{x} \frac{\Lambda}{H_{s}} u_{g, \gamma}^{g} k\right]^{1-\gamma_{2}^{s}}\right\}^{1-\gamma_{1}^{s}}, \\
& g=\lambda_{g}\left(\gamma_{1}^{g} u_{g, \gamma}^{g}\right)^{\gamma_{1}^{g}} \\
& \times\left\{\left(u_{g}^{s}\right)^{\gamma_{2}^{g}}\left[\left(1-\gamma_{1}^{g}\right)\left(1-\gamma_{2}^{g}\right)\left(\gamma_{1}^{s}+\gamma_{3} \gamma_{1}^{\Lambda} x\right) \frac{1}{x} \frac{\Lambda}{H_{s}} \frac{u_{g, \gamma}^{g}}{u_{s}^{g}} k u_{g, \gamma}^{g}\right]^{1-\gamma_{2}^{g}} \frac{H_{s}}{H_{g}}\right\}^{1-\gamma_{1}^{g}}, \\
& \frac{\Lambda}{H_{s}}=\frac{1}{g} \lambda_{\Lambda}\left(u_{s}^{g} \frac{H_{g}}{H_{s}}\right)^{\gamma_{1}^{\Lambda}}\left(u_{s}^{s}\right)^{1-\gamma_{1}^{\Lambda}}, \\
& \frac{1}{u_{g, \gamma}^{g}} x=\frac{\left(1-\gamma_{2}\right)}{\left(1+\tau_{Y}^{s}\right) \gamma_{2}}\left[\left(1-\gamma_{1}^{s}\right) \gamma_{2}^{s}+\gamma_{3}\left(1-\gamma_{1}^{\Lambda}\right) x\right] \frac{1-u_{s}^{s}-u_{g}^{s}}{u_{s}^{s}} \\
& +\left(1-\gamma_{1}^{s}\right)\left(1-\gamma_{2}^{s}\right)+\left(1-\gamma_{1}^{g}\right)\left(1-\gamma_{2}^{g}\right)\left(\gamma_{1}^{s}+\gamma_{3} \gamma_{1}^{\Lambda} x\right) \frac{u_{g, \gamma}^{g}}{u_{s}^{g}} \\
& \frac{1-u_{s}^{s}-u_{g}^{s}}{u_{s}^{s}}=\frac{\left(1-\gamma_{1}\right)\left(1+\tau_{Y}^{s}\right) \gamma_{2}}{\left(1+\tau_{Y}^{g}\right) \gamma_{1}} \frac{\gamma_{1}^{s}+\gamma_{3} \gamma_{1}^{\Lambda} x}{\left(1-\gamma_{1}^{s}\right) \gamma_{2}^{s}+\gamma_{3}\left(1-\gamma_{1}^{\Lambda}\right) x} \frac{1-u_{s}^{g}-\gamma_{1}^{g} u_{g, \gamma}^{g}}{u_{s}^{g}} .
\end{aligned}
$$

The remainder of the variables can be solved from the following equations

$$
\begin{aligned}
& \frac{q_{3}}{q_{2}}=\frac{H_{s}}{H_{g}}\left(\gamma_{1}^{s}+\gamma_{3} \gamma_{1}^{\Lambda} x\right) \frac{u_{g, \gamma}^{g}}{u_{s}^{g}}, \\
& u_{s}^{K}=\frac{1}{x}\left(1-\gamma_{1}^{s}\right)\left(1-\gamma_{2}^{s}\right) u_{g, \gamma}^{g}, \\
& u_{g}^{K}=\frac{\left(1-\gamma_{1}^{g}\right)\left(1-\gamma_{2}^{g}\right)}{\left(1-\gamma_{1}^{s}\right)\left(1-\gamma_{2}^{s}\right)}\left(\gamma_{1}^{s}+\gamma_{3} \gamma_{1}^{\Lambda} x\right) \frac{u_{g, \gamma}^{g}}{u_{s}^{g}} u_{s}^{K}, \\
& u_{Y}^{K}=1-u_{s}^{K}-u_{g}^{K}, \\
& u_{Y}^{s}=1-u_{s}^{s}-u_{g}^{s}, \\
& u_{Y}^{g}=1-u_{s}^{g}-\gamma_{1}^{g} u_{g, \gamma}^{g},
\end{aligned}
$$


and

$$
\begin{aligned}
& \frac{Y}{H_{s}}=\frac{\lambda_{Y}\left(u_{Y}^{g} H_{g}\right)^{\gamma_{1}}\left[\left(u_{Y}^{s} H_{s}\right)^{\gamma_{2}}\left(u_{Y}^{K} \Lambda k\right)^{1-\gamma_{2}}\right]^{1-\gamma_{1}}}{H_{s}}, \\
& \frac{q_{1}}{q_{2}}=\frac{\left(1-\gamma_{1}^{s}\right)\left(1-\gamma_{2}^{s}\right)}{\left(1-\gamma_{1}\right)\left(1-\gamma_{2}\right)} g \frac{u_{Y}^{K}}{u_{s}^{K}} \frac{H_{s}}{Y}, \\
& x=\frac{q_{4}}{q_{2}} \frac{\Lambda}{H_{s}}, \\
& u_{g}^{g}=\gamma_{1}^{g} u_{g, \gamma}^{g} .
\end{aligned}
$$

We perform comparative statics for the share of specific human capital, $\frac{H_{s}}{H_{g}+H_{s}}$, the share of specific human capital allocated to its accumulation, $u_{s}^{s}$, and the growth rate of final output, $g$, with respect to $\gamma_{3}$. We use numerical methods to perform these comparative statics, where we set

$$
\begin{aligned}
& \lambda_{s}=\lambda_{\Lambda}=0.1, \lambda_{g}=0.67, \\
& \theta=1, \rho=0.05, \\
& \gamma_{1}^{s}=\gamma_{1}^{g}, \gamma_{2}^{s}=\gamma_{2}^{g},
\end{aligned}
$$

and allow all parameters $\gamma$ to vary in between $[0.1,0.9]$. In this exercise, we form a multidimensional grid of parameter values using 5 equidistant points from each interval.

We find that $g$ increases with $\gamma_{3}$. We also find that $\frac{H_{s}}{H_{g}+H_{s}}$ and $u_{s}^{s}$ increase with $\gamma_{3}$ when $\gamma_{1}^{\Lambda} \in$ $[0,0.2], \gamma_{1}^{s} \in[0.1,0.4]$, and $\gamma_{2}^{s} \in[0.6,0.9]$. This combination of values of $\gamma_{1}^{s}$ and $\gamma_{2}^{s}$ corresponds to the case when the shares of general human capital and physical capital in education are lower than the share of specific human capital. However, there are $\left\{\gamma_{1}^{\Lambda}, \gamma_{1}^{s}, \gamma_{2}^{s}\right\}$ points from $\{[0.2,0.9],[0.4,0.9],[0.1,0.6]\}$ where $\frac{H_{s}}{H_{g}+H_{s}}$ declines with $\gamma_{3}$. 


\section{Appendix - Tables and Figures}

Table 9: Analytical Comparative Statics

\begin{tabular}{l|lllllllll} 
& $q_{4} / q_{2}$ & $q_{3} / q_{2}$ & $H_{s} / H_{g}$ & $H_{s} / \Lambda$ & $g$ & $u_{s}^{s}$ & $u_{g}^{s}$ & $u_{Y}^{s}$ & $u_{s}^{s} / u_{g}^{s}$ \\
\hline \hline$\rho$ & + & + & & 0 & & & & & \\
$\theta$ & & & - & 0 & - & - & & - \\
$\gamma_{1}$ & - & - & - & 0 & - & - & & & \\
$\gamma_{2}$ & & & & 0 & & & & \\
$\gamma_{3}$ & & & + & 0 & + & + & & & + \\
$\lambda_{s}$ & & & + & + & & & & & \\
$\lambda_{g}$ & 0 & - & - & 0 & 0 & 0 & 0 & 0 & 0 \\
$\lambda_{s}, \lambda_{s} \equiv \lambda_{g}$ & & & & & & & & & \\
$\lambda_{\Lambda}$ & - & 0 & 0 & - & 0 & 0 & 0 & 0 & 0 \\
$\tau_{Y}^{s}$ & & & & 0 & & & & & \\
$\tau_{Y}^{s}, \tau_{Y}^{g} \equiv \tau_{Y}^{s}$ & - & - & - & 0 & - & - & & & - \\
\hline
\end{tabular}

Note: The sign + means a positive relationship, - negative, and 0 means no relationship.

Table 10: Comparative Statics $-\gamma_{3}=0$

\begin{tabular}{l|llllllll} 
& $q_{3} / q_{2}$ & $H_{s} / H_{g}$ & $H_{s} / \Lambda$ & $g$ & $u_{s}^{s}$ & $u_{g}^{s}$ & $u_{Y}^{s}$ & $u_{s}^{s} / u_{g}^{s}$ \\
\hline \hline$\rho$ & 0 & - & 0 & - & - & \pm & + & - \\
$\theta$ & 0 & - & 0 & - & - & \pm & + & - \\
$\gamma_{1}$ & 0 & - & 0 & 0 & 0 & + & - & - \\
$\gamma_{2}$ & 0 & + & 0 & 0 & 0 & - & + & + \\
$\lambda_{s}$ & + & + & + & + & + & \pm & - & + \\
$\lambda_{g}$ & - & - & 0 & 0 & 0 & 0 & 0 & 0 \\
$\lambda_{s}, \lambda_{s} \equiv \lambda_{g}$ & 0 & + & + & + & + & \pm & - & + \\
$\lambda_{\Lambda}$ & 0 & 0 & - & 0 & 0 & 0 & 0 & 0 \\
$\tau_{Y}^{s}$ & 0 & + & 0 & 0 & 0 & - & + & + \\
$\tau_{Y}^{s}, \tau_{Y}^{g} \equiv \tau_{Y}^{s}$ & 0 & 0 & 0 & 0 & 0 & 0 & 0 & 0 \\
\hline
\end{tabular}

Note: The sign + means a positive relationship, - negative, 0 no relationship, and \pm means that the relationship depends on model parameters. 
Table 11: Comparative Statics - R\&D Intensity is a Choice Variable

\begin{tabular}{l|llllllllll} 
& $q_{4} / q_{2}$ & $q_{3} / q_{2}$ & $H_{s} / H_{g}$ & $H_{s} / \Lambda$ & $g$ & $u_{s}^{s}$ & $u_{g}^{s}$ & $u_{Y}^{s}$ & $u_{\Lambda}^{s}$ & $u_{s}^{s} / u_{g}^{s}$ \\
\hline \hline$\rho$ & 0 & 0 & - & - & - & - & \pm & + & \pm & - \\
$\theta$ & 0 & 0 & - & - & - & - & \pm & + & \pm & - \\
$\gamma_{1}$ & 0 & 0 & - & + & 0 & 0 & + & - & - & - \\
$\gamma_{2}$ & 0 & 0 & + & + & 0 & 0 & - & + & - & + \\
$\gamma_{3}$ & - & 0 & + & - & 0 & 0 & - & - & + & - \\
$\lambda_{s}$ & + & + & + & + & + & + & \pm & - & \pm & + \\
$\lambda_{g}$ & 0 & - & - & 0 & 0 & 0 & 0 & 0 & 0 & 0 \\
$\lambda_{s}, \lambda_{s} \equiv \lambda_{g}$ & + & 0 & + & + & + & + & \pm & - & \pm & + \\
$\lambda_{\Lambda}$ & - & 0 & 0 & - & 0 & 0 & 0 & 0 & 0 & 0 \\
$\tau_{Y}^{s}$ & 0 & 0 & + & + & 0 & 0 & - & + & - & + \\
$\tau_{Y}^{s}, \tau_{Y}^{g} \equiv \tau_{Y}^{s}$ & 0 & 0 & - & + & 0 & 0 & + & + & - & - \\
\hline
\end{tabular}

Note: The sign + means a positive relationship, - negative, 0 no relationship, and \pm means that the relationship depends on model parameters. 
Figure 2: Stable Manifold in $\left(u_{Y}^{s}, \omega_{2}\right)$ Space

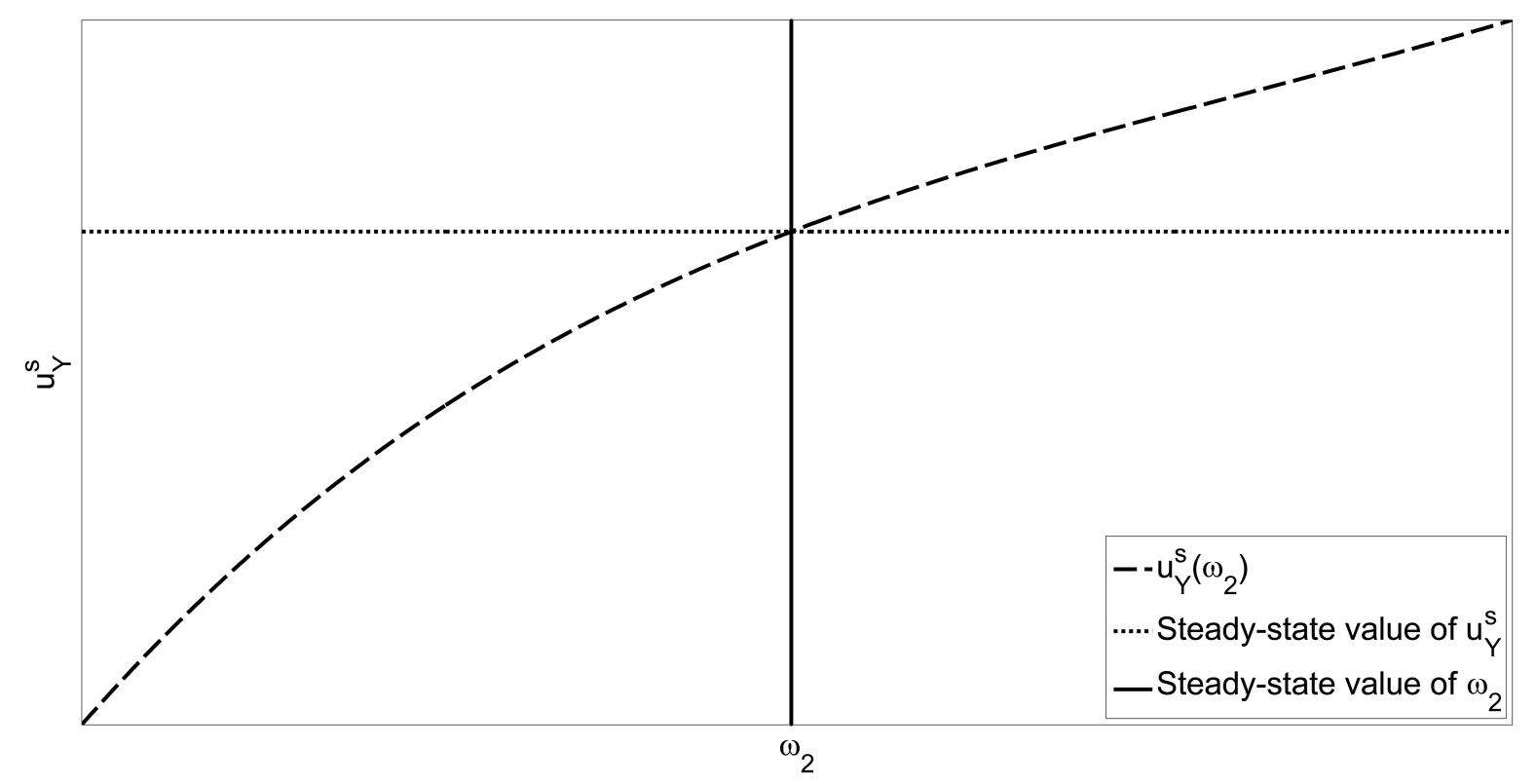

Note: This figure offers simulated stable manifold in $\left(u_{Y}^{s}, \omega_{2}\right)$ space. 